\title{
CHASE-PL Climate Projection dataset over Poland - bias adjustment of EURO-CORDEX simulations
}

\author{
Abdelkader Mezghani ${ }^{1}$, Andreas Dobler ${ }^{1}$, Jan Erik Haugen ${ }^{1}$, Rasmus E. Benestad ${ }^{1}$, Kajsa M. Parding ${ }^{1}$, \\ Mikołaj Piniewski $^{2,3}$, Ignacy Kardel ${ }^{2}$, and Zbigniew W. Kundzewicz ${ }^{3,4}$ \\ ${ }^{1}$ Norwegian Meteorological Institute, Henrik Mohns plass 1, 0313 Oslo, Norway \\ ${ }^{2}$ Department of Hydraulic Engineering, Warsaw University of Life Sciences, \\ Nowoursynowska 166, 02-787 Warsaw, Poland \\ ${ }^{3}$ Potsdam Institute for Climate Impact Research, Telegrafenberg, 14473 Potsdam, Germany \\ ${ }^{4}$ Institute for Agricultural and Forest Environment of the Polish Academy of Sciences, \\ Bukowska 19, 60-809 Poznań, Poland
}

Correspondence to: Abdelkader Mezghani (abdelkaderm@met.no)

Received: 8 June 2017 - Discussion started: 19 July 2017

Revised: 16 October 2017 - Accepted: 18 October 2017 - Published: 28 November 2017

\begin{abstract}
The CHASE-PL (Climate change impact assessment for selected sectors in Poland) Climate Projections - Gridded Daily Precipitation and Temperature dataset $5 \mathrm{~km}$ (CPLCP-GDPT5) consists of projected daily minimum and maximum air temperatures and precipitation totals of nine EURO-CORDEX regional climate model outputs bias corrected and downscaled to a $5 \mathrm{~km} \times 5 \mathrm{~km}$ grid. Simulations of one historical period (19712000) and two future horizons (2021-2050 and 2071-2100) assuming two representative concentration pathways (RCP4.5 and RCP8.5) were produced. We used the quantile mapping method and corrected any systematic seasonal bias in these simulations before assessing the changes in annual and seasonal means of precipitation and temperature over Poland. Projected changes estimated from the multi-model ensemble mean showed that annual means of temperature are expected to increase steadily by $1^{\circ} \mathrm{C}$ until $2021-2050$ and by $2^{\circ} \mathrm{C}$ until $2071-2100$ assuming the RCP4.5 emission scenario. Assuming the RCP8.5 emission scenario, this can reach up to almost $4{ }^{\circ} \mathrm{C}$ by $2071-2100$. Similarly to temperature, projected changes in regional annual means of precipitation are expected to increase by 6 to $10 \%$ and by 8 to $16 \%$ for the two future horizons and RCPs, respectively. Similarly, individual model simulations also exhibited warmer and wetter conditions on an annual scale, showing an intensification of the magnitude of the change at the end of the 21 st century. The same applied for projected changes in seasonal means of temperature showing a higher winter warming rate by up to $0.5^{\circ} \mathrm{C}$ compared to the other seasons. However, projected changes in seasonal means of precipitation by the individual models largely differ and are sometimes inconsistent, exhibiting spatial variations which depend on the selected season, location, future horizon, and RCP. The overall range of the $90 \%$ confidence interval predicted by the ensemble of multi-model simulations was found to likely vary between $-7 \%$ (projected for summer assuming the RCP4.5 emission scenario) and $+40 \%$ (projected for winter assuming the RCP8.5 emission scenario) by the end of the 21 st century. Finally, this high-resolution bias-corrected product can serve as a basis for climate change impact and adaptation studies for many sectors over Poland. The CPLCP-GDPT5 dataset is publicly available at http://dx.doi.org/10.4121/uuid:e940ec1a-71a0-449e-bbe3-29217f2ba31d.
\end{abstract}




\section{Introduction}

Regional climate change projections for all terrestrial regions of the globe within the time line of the Fifth Assessment Report (AR5) and beyond have been made available for climate researchers in the framework of the CORDEX initiative. Within this initiative, a large ensemble of highresolution regional climate projections including Europe (EURO-CORDEX, the European branch of the CORDEX initiative) have been made available to provide climate simulations for use in climate change impact, adaptation, and mitigation studies (Giorgi and Lionello, 2008). Although most of the simulations are run on a high grid resolution, systematic biases in the regional climate models (RCMs) remain, due to errors related to (i) imperfect model representation of the physical processes or phenomena and (ii) to the parametrization and incorrect initialization of the models. Thus, even when using the highest resolution available, RCMs still require some adjustments (Christensen et al., 2008; Muerth et al., 2013). Therefore, bias correction methods continue to be used in impact studies - for example in hydrology (e.g. Chen et al., 2013; Teutschbein and Seibert, 2012), agronomy (e.g. Ines and Hansen, 2006), ecology, and more recently by climate services (e.g. Sorteberg et al., 2014) - to reduce systematic bias in (regional or global) climate models.

Traditionally, the bias correction method ensures equal mean values between the corrected simulations and observations (e.g. Déqué et al., 2007) - hence, explicitly addressing only one aspect of the statistical properties of the simulated data. More advanced methods consider the whole distribution of a weather variable to be adjusted, including extremes, so that it matches the distribution of the observations (e.g. Themeß1 et al., 2010; Berg et al., 2012; Lafon et al., 2013).

Recent studies have compared different RCM bias correction methods. Themeßl et al. (2010) evaluated seven bias correction methods used to correct modelled precipitation by the RCM MM5 using forcings from ERA-40 reanalysis. They concluded that quantile mapping outperforms all methods considered, especially at high quantiles. Berg et al. (2012) applied three bias correction methods to correct the mean and variance of precipitation and temperature modelled by the RCM COSMO-CLM driven by the ECHAM5-MPIOM global climate model (GCM) over all of Germany and nearby surrounding areas, modelled at $7 \mathrm{~km}$ resolution and validated against 30 years of $1 \mathrm{~km}$ gridded observation data (19712000). They found that some of the methods correct not only the means but also the higher moments. Gudmundsson et al. (2012) confirmed that non-parametric methods such as quantile mapping are more suitable in reducing systematic errors in model data. They compared 11 bias correction methods used to correct precipitation modelled by RCM HIRAM forced with the ERASE reanalysis data and found that non-parametric methods performed the best in reducing systematic errors, followed by parametric transformations with three or more free parameters, with the lowest rank taken by the distribution-derived transformations. Teutschbein and Seibert (2012) applied six bias correction methods to correct 11 different RCM-simulated temperature and precipitation series, and found that all methods were able to preserve the mean - however, other statistical properties were degraded. Lafon et al. (2013) applied four distribution-based bias correction methods to correct precipitation modelled by the RCM HadRM3-PPEUK driven by the GCM HadCM3 over seven catchments in Great Britain. They found that gamma-based quantile mapping offers the best combination of accuracy when evaluated on the first four order moments (mean, SD, skewness, and kurtosis). Sorteberg et al. (2014) tested six distribution-based bias correction methods. They found that all evaluated methods perform reasonably well in (i) reproducing statistical properties of the observations including high-order moments and quantiles and (ii) preserving the climate change signal.

Bias correction methods can also be categorized into parametric and non-parametric methods. In the parametric methods the distribution of the data is assumed to be known. For instance, it is well known that the probability distribution of daily temperature values follows a normal distribution (Buishand and Brandsma, 1997), whereas the exponential (Benestad et al., 2005) and gamma distributions (Buishand and Brandsma, 2001) are often used to model the intensity of daily precipitation. Likewise, the Bernoulli and geometric distributions are often used to model the probability distribution of the occurrence of daily precipitation (frequency) and the number of consecutive dry/wet days, respectively (Buishand and Beckmann, 2000). On the other hand, the non-parametric methods are applied without prior assumptions about the distribution of the data (Lanzante, 1996). Hence, they are more attractive for many applications including those based on bias correction. Another advantage is that non-parametric methods are more suitable in reducing systematic errors in model data (Gudmundsson et al., 2012).

Among existing methods, the non-parametric quantile mapping method, referred to as quantile mapping (QM) for simplicity, has shown a good performance in reproducing not only the mean and the SD but also other statistical properties such as quantiles (Fang et al., 2015). As the method belongs to the non-parametric family, it does not require prior knowledge of the theoretical distribution of the weather variable, which makes it very attractive, as it is easy to implement, in addition to its simple and non-parametric configuration (Gudmundsson et al., 2012).

However, the QM has a few limitations. It is particularly sensitive to the choice and the length of the calibration time period to make a reliable estimation not affected by data sampling problems (Fowler and Kilsby, 2007). Thus, it requires a reference dataset to adjust the modelled data to match the observations (Lafon et al., 2013). It is sometimes difficult to apply this method to different climatic conditions, as unobserved values may lie outside the range of those in the cali- 
bration time period (Themeß1 et al., 2010) (i.e. values in the tail of the distribution). Another issue is related to the misrepresentation of the (physical) link between weather variables, which can be altered especially if applied to each climate variable separately. For instance, in most hydrological applications the dependence between daily precipitation and temperature can affect the discharge (Haerter et al., 2011).

A few studies related to projections of climate change have been dedicated to Poland. For instance, climate projections originating from the ENSEMBLES project (Linden and Mitchell, 2009) were used as the basis to investigate the impact of climate change on various sectors (agriculture, water resources, and health) in Europe. Szwed et al. (2010) assessed six regional climate model simulations under the SRES A2 emission scenario and found unfavourable changes in Polish climate, such as an increased frequency of extreme events, reduced crop yields, and increased summer water budget deficit. In the "KLIMADA" project, the ENSEMBLES projections were additionally bias-adjusted (http: //klimada.mos.gov.pl/en/) within the framework of the Polish National Adaptation Strategy to Climate Change (NAS 2020) to estimate changes in climate variables and indices for two future horizons - the near future (2021-2050) and the far future (2071-2100). The outcomes of the latter project showed significant upward trend in temperature and uncertain precipitation increases in the median of winter changes, and slight decreases in summer (Osuch et al., 2012). Piotrowski and Jędruszkiewicz (2013) assessed the spatial variability in winter temperature over Poland for the near future (2021-2050) based on three RCMs under the SRES A1B emission scenario. More recently, Osuch et al. (2016) applied a bias correction method on six simulations from the ENSEMBLES project to assess various drought indices over Poland and pointed out that the correction process altered the magnitude of the trend in corrected modelled precipitation but not its direction.

There have also been a few studies carried out for Poland based on the newest generation of climate model simulations (i.e. the fifth generation of the Coupled Model Intercomparison Project (CMIP5) and the European domain of the Coordinated Downscaling Experiment Initiative (EUROCORDEX)). Romanowicz et al. (2016) used bias-adjusted modelled temperature and precipitation (seven GCM-RCM combinations from the EURO-CORDEX initiative over 10 Polish catchments) and found that projections following the RCP4.5 emission scenario agreed on a precipitation increase of up to $15 \%$, and a warming of up to $2{ }^{\circ} \mathrm{C}$ by the end of the 21 st century. Pluntke et al. (2016) applied a statistical downscaling model to produce temperature and precipitation projections from two global climate models following three different emission scenarios (RCP2.6, RCP8.5, and SRES A1B) for the southwest of Poland and eastern Saxony. They found an acceleration of changes by the end of the 21 st century leading to negative consequences for the climatic water bal- ance, particularly under SRES A1B and RCP8.5 emission scenarios.

The main objective of this paper is to provide an update of climate projections over Poland by adopting the new generation of concentration pathways and recent developments in climate modelling. We hope the dataset provided here will be beneficial for the research community - for instance for impact studies in areas such as hydrology, ecology and agricultural sciences. In this paper we also use a recently made available high-resolution gridded observational dataset (CPLFDGDPT5; see Sect. 2) covering more than 60 years as a reference for the bias correction procedure (Sect. 3.1).

\section{Input datasets}

In the present study two types of datasets were used:

(1) a Polish high-resolution observational climate dataset used as reference for the bias correction and

(2) a (multi-model) ensemble of RCM simulations provided through the EURO-CORDEX experiment.

\subsection{Polish high-resolution observational climate dataset}

The gridded daily precipitation and temperature dataset (CPLFD-GDPT5) is used here as reference or pseudoobservational data in the bias adjustment procedure (Berezowski et al., 2016). The dataset consists of a $5 \mathrm{~km} \times 5 \mathrm{~km}$ gridded product of daily precipitation, minimum air temperature, and maximum air temperature. The spatial extent of the CPLFD-GDPT5 is the union of two intersecting areas: the Vistula and Odra river basins and Poland's territory. It covers the period from 1951 to 2013 (63 years). Berezowski et al. (2016) evaluated the CPLFD-GDPT5 data on reproducing observed Polish climate and concluded that the new high-resolution gridded product showed a good consistency with previous products, although small differences arose due to the assimilation of new sets of meteorological stations and the use of a different interpolation technique. Piniewski et al. (2017b) used this dataset as inputs in hydrological modelling of the Vistula and Odra river basins and reported satisfactory model performance in simulating daily discharges in 110 flow gauges. To our knowledge, it is the best currently available climatic dataset that could be used as reference in bias correction in this study. For simplicity, it will be hereafter referred to as "observations".

\subsection{RCM simulations}

The RCM simulations, referred to hereafter as "simulations", consist of nine historical simulations spanning the time period from 1949 to 2005 and of 18 model simulations spanning the future time period from 2006 to 2100 provided within the EURO-CORDEX initiative. From these simulations, we extracted daily minimum and maximum tempera- 
Table 1. GCM/RCM simulations.

\begin{tabular}{llllllrr}
\hline$N$ & $\begin{array}{l}\text { Global climate model } \\
\text { Institute }\end{array}$ & Model & Run & $\begin{array}{l}\text { Regional climate model } \\
\text { Institute }\end{array}$ & Model & $\begin{array}{r}\text { Period } \\
\text { From }\end{array}$ & To \\
\hline 1 & CNRM-CERFACS & CNRM-CM5 & r1i1p1 & CLMcom & CCLM4-8-17 & 1 Jan 1950 & 31 Dec 2100 \\
2 & CNRM-CERFACS & CNRM-CM5 & r1i1p1 & SMHI & RCA4 & 1 Jan 1970 & 31 Dec 2100 \\
3 & ICHEC & EC-EARTH & r12i1p1 & CLMcom & CCLM4-8-17 & 1 Dec 1949 & 31 Dec 2100 \\
4 & ICHEC & EC-EARTH & r12i1p1 & SMHI & RCA4 & 1 Jan 1970 & 31 Dec 2100 \\
5 & ICHEC & EC-EARTH & r1i1p1 & KNMI & RACMO22E & 1 Jan 1950 & 31 Dec 2100 \\
6 & ICHEC & EC-EARTH & r3i1p1 & DMI & HIRHAM5 & 1 Jan 1951 31 Dec 2100 \\
7 & IPSL & IPSL-CM5A-MR & r1i1p1 & SMHI & RCA4 & 1 Jan 1970 31 Dec 2100 \\
8 & MPI-M & MPI-ESM-LR & r1i1p1 & CLMcom & CCLM4-8-17 & 1 Jan 1970 31 Dec 2100 \\
9 & MPI-M & MPI-ESM-LR & r1i1p1 & SMHI & RCA4 & 1 Dec 1949 31 Dec 2100 \\
\hline
\end{tabular}

tures and precipitation on grid cells belonging to the same spatial domain as the observations - i.e. the area of Poland and parts of the Vistula and Odra basins belonging to neighbouring countries. This domain corresponds to the area from 13.1 to $26.1^{\circ} \mathrm{E}$ and 48.6 to $54.9^{\circ} \mathrm{N}$. The total number of grid cells equals $N_{\mathrm{g}}=23016(168 \times 137)$. Selected simulations consisted of the combination of four GCMs and four RCMs following the two representative concentration pathways RCP4.5 and RCP8.5 and are presented in Table 1. We also focused on three common time slices spanning the period 1971-2000 (referred to hereafter as control period) and two future horizons 2021-2050 and 2071-2100 referred to hereafter as near and far future, respectively. As those simulations were made available on different spatial resolutions, an interpolation onto the same $5 \mathrm{~km} \times 5 \mathrm{~km}$ grid as for observations was performed before the bias correction method was applied. For this purpose, we used the nearest-neighbour interpolation method, which means that each cell in the new grid (in this case the $5 \mathrm{~km} \times 5 \mathrm{~km}$ high resolution) was assigned the RCM values of the nearest grid cell in their original grid resolution. We did not correct the interpolated values for altitudinal variations as this was already included in the observational gridded dataset.

\section{Data analyses}

\subsection{Bias correction method}

We used the quantile mapping to correct for systematic biases in RCM simulations. The quantile mapping tries to find a statistical transformation or function $F$ that maps a simulated variable $y$ such that its new distribution closely fits the distribution of the observed variable $x$. In general, this transformation can be formulated as

$x=F(y)$.

The non-parametric transformation is then defined as (Piani and Haerter, 2012)

$x=F^{-1}(G(y))$,

where $G$ is the cumulative distribution function of $y$ and $F^{-1}$ is the inverse cumulative distribution function corresponding to $x$. The quantile mapping of the simulated time series to the observed ones was performed for each grid cell. Here, the number of quantiles was set to $N_{\mathrm{q}}=1000$ and was chosen to be regularly spaced. Two steps were performed. First, RCM corresponding quantiles were taken from the empirical cumulative distribution function based on observations. Second, these estimates were used to perform a quantile mapping. It should be noted that the set-up included a linear interpolation between the fitted transformed values and simulated values lying outside the range of observed values in the training period. Hence, they were extrapolated using the correction found for the highest percentile as suggested by Boé et al. (2007). Furthermore, the method included an adjustment of wet-day frequencies for precipitation. Here, a wet day was defined as a day with a precipitation amount higher than $0 \mathrm{~mm} \mathrm{day}^{-1}$. The probability of wet days was first derived from observations, and then used as a threshold, so that all modelled values below this threshold were set to zero. This ensured an equal fraction of rainy days between observed and modelled data. The transformations were, additionally, fitted to the portion of the distributions corresponding to observed wet days. The quantile mapping method was applied on each of the four seasons separately to take into account seasonality in the biases, as different seasons may be influenced by different physical processes. Then, the output data were merged to reconstruct a full simulation. As discussed in Sect. 1, the quantile mapping may modify the link between individually post-processed climate variables. However, correcting the present climate to be closer to the observations has been necessary for most climate change impact studies (Sorteberg et al., 2014). Quantiles of the simulations for the control period (1971-2000) were mapped onto corresponding quantiles in the observations considered as the most recent 63-year reference time period (1951-2013). The transfer functions were then used to correct for the bias in the daily minimum and maximum temperatures and precipitation simulations defined in Table 1. 
Table 2. RMSEs in annual and seasonal means of monthly sums of precipitation ( $\left.\mathrm{mm} \mathrm{month}^{-1}\right)$. The RMSEs were computed between historical simulations and observations and averaged over all grid cells.

\begin{tabular}{llrrrrr}
\hline$N$ & GCM/RCM simulation & Annual & Winter & Spring & Summer & Autumn \\
\hline 1 & CNRM-CM5/CCLM4-8-17 & 13.5 & 11.7 & 7.0 & 45.2 & 8.5 \\
2 & CNRM-CM5/RCA4 & 15.1 & 14.5 & 19.5 & 27.3 & 12.2 \\
3 & EC-EARTH/CCLM4-8-17 & 12.6 & 12.2 & 8.1 & 28.5 & 10.2 \\
4 & EC-EARTH/RCA4 & 14.6 & 15.8 & 17.6 & 24.3 & 11.4 \\
5 & EC-EARTH/RACMO22E & 13.1 & 14.7 & 13.1 & 20.3 & 9.8 \\
6 & EC-EARTH/HIRHAM5 & 19.4 & 21.7 & 18.4 & 22.7 & 20.9 \\
7 & IPSL-CM5A-MR/RCA4 & 23.2 & 21.64 & 33.9 & 27.3 & 19.9 \\
8 & MPI-ESM-LR/CCLM4-8-17 & 8.7 & 13.2 & 8.7 & 13.3 & 10.0 \\
9 & MPI-ESM-LR/RCA4 & 19.4 & 14.8 & 26.6 & 29.1 & 16.2 \\
\hline Ens. mean* & All & 15.5 & 15.6 & 17.0 & 26.4 & 13.2 \\
Ens. SD & All & 4.4 & 3.7 & 9.0 & 8.6 & 4.7 \\
\hline
\end{tabular}

* Ens. stands for ensemble, SD for standard deviation.

\subsection{Biases in RCM simulations}

Each of the nine bias-corrected historical simulations was evaluated on its ability to reproduce statistical properties of the pseudo-observed or reference dataset. In our case, averaged error values $(e)$ over time $(t)$ for each grid cell in terms of RMSEs were considered as a measure of the model's performance. As model errors are often seasonally dependent, the four seasons are treated separately. For a time $t$ (seasonal or annual), the model error is calculated as

$e_{\mathrm{t}}=s_{\mathrm{t}}-o_{\mathrm{t}}$,

where $s$ and $o$ refer to simulated and observed values. The RMSE averaged over space is then defined as

RMSE $=\sqrt{\frac{1}{N_{\mathrm{g}}} \sum_{i=1}^{N_{\mathrm{g}}} e_{\mathrm{t}}^{2}}$,

where $N_{\mathrm{g}}$ is the total number of grid cells.

The averaged RMSE informs about the magnitude of the overall deviation between the simulations and pseudoobservations over all Poland, while the error $(e)$ indicates whether there was an over- (positive) or under- (negative) estimation (bias) of the simulated values at each grid cell.

The RMSE was computed between values of biascorrected and raw monthly sums of precipitation, daily minimum and maximum temperatures, and their corresponding observations. The model error was first computed on each grid cell, then mapped across Poland and averaged from the spatial field only - i.e. with the RMSE of the temporal means of all grid cells, not of the single grid cells.

Tables 2 to 4 gives the mean and SD of the RMSE derived from the ensemble of model simulations.

The RMSE in annual means averaged over all raw simulations (i.e. multi-model ensemble mean) was $15.5 \pm$ $4.4 \mathrm{~mm} \mathrm{month}^{-1}$ for precipitation and $1.1 \pm 0.7^{\circ} \mathrm{C}$ and $1.6 \pm$ $0.45^{\circ} \mathrm{C}$ for daily minimum and maximum temperatures, respectively (Tables 2 to 3 ). For seasonal means, the largest error was found in summer precipitation $(26.4 \pm$ $8.6 \mathrm{~mm} \mathrm{month}^{-1}$ ), mainly due to the convection, not well represented in the climate models. The lowest error was found in the autumn, where precipitation is influenced by continental air masses. The same tendency was additionally found for daily maximum temperature, i.e. large error in the summer compared to the other seasons. However, for daily minimum temperature, the largest error of $1.5^{\circ} \mathrm{C}$ was obtained for spring, followed by summer with a slightly lower bias of $1.3{ }^{\circ} \mathrm{C}$. In general, biases in daily maximum temperature were 0.5 to $1{ }^{\circ} \mathrm{C}$ higher than those found in daily minimum temperature. The lowest precipitation bias was simulated by the regional atmospheric model RCA4 driven by the global model M-MPI-ESM-LR (Simulation 8 in Table 2). Obviously, these biases or model errors might be related to the complexity of the climate system in Poland, which has been very difficult to predict, being influenced by air masses from all four directions (Kundzewicz and Matczak, 2012).

Moreover, model errors or biases are often spatially dependant and varied among the simulations and seasons. In our case, all historical simulations showed wet and warm biases as well as dry and cold biases across the region, which were more pronounced in the mountainous areas located in the southern parts of Poland, due to topographical features not well represented in the models (Figs. 1-27 in the Supplement). This can also be related to the low observational network density in this region. As we did not intend to perform a thorough comparison between all model simulations, only an example of the bias in the RCM CCLM4-8-17 driven by the CNRM-CM5 GCM for the historical climate (Simulation 1 in Table 1) is detailed here (Figs. 1-3).

For precipitation, seasonal evaluations additionally showed that the relatively high RMSE found in the raw data on an annual scale $\left(13.5 \mathrm{~mm} \mathrm{month}^{-1}\right)$ was due to high 
Table 3. RMSEs in annual and seasonal means of daily maximum temperature $\left({ }^{\circ} \mathrm{C}\right)$. RMSEs were computed between historical simulations and observations and averaged over all grid cells.

\begin{tabular}{llrrrrr}
\hline$N$ & GCM/RCM simulation & Annual & Winter & Spring & Summer & Autumn \\
\hline 1 & CNRM-CM5/CCLM4-8-17 & 1.5 & 2.4 & 2.8 & 1.6 & 1.6 \\
2 & CNRM-CM5/RCA4 & 1.3 & 1.6 & 2.8 & 1.1 & 0.6 \\
3 & EC-EARTH/CCLM4-8-17 & 1.6 & 1.5 & 1.8 & 1.6 & 2.0 \\
4 & EC-EARTH/RCA4 & 1.8 & 1.1 & 2.4 & 2.8 & 1.3 \\
5 & EC-EARTH/RACMO22E & 1.9 & 0.9 & 2.7 & 2.7 & 1.8 \\
6 & EC-EARTH/HIRHAM5 & 2.4 & 1.5 & 2.1 & 3.4 & 2.8 \\
7 & IPSL-CM5A-MR/RCA4 & 1.7 & 0.7 & 3.3 & 2.8 & 1.0 \\
8 & MPI-ESM-LR/CCLM4-8-17 & 1.8 & 1.3 & 1.4 & 2.8 & 1.9 \\
9 & MPI-ESM-LR/RCA4 & 0.8 & 0.8 & 0.9 & 2.1 & 0.6 \\
\hline Ens. mean* & All & 1.6 & 1.3 & 2.3 & 2.3 & 1.5 \\
Ens. SD* & All & 0.5 & 0.5 & 0.8 & 0.7 & 0.7 \\
\hline
\end{tabular}

* Ens. stands for ensemble, SD for standard deviation.

Table 4. RMSEs in annual and seasonal means of daily minimum temperature $\left({ }^{\circ} \mathrm{C}\right)$. The RMSEs were computed between historical simulations and observations and averaged over all grid cells.

\begin{tabular}{llrrrrr}
\hline$N$ & GCM/RCM simulation & Annual & Winter & Spring & Summer & Autumn \\
\hline 1 & CNRM-CM5/CCLM4-8-17 & 0.7 & 1.3 & 1.0 & 2.3 & 0.8 \\
2 & CNRM-CM5/RCA4 & 1.13 & 1.7 & 1.9 & 0.7 & 0.9 \\
3 & EC-EARTH/CCLM4-8-17 & 0.6 & 0.7 & 0.6 & 0.9 & 0.8 \\
4 & EC-EARTH/RCA4 & 1.4 & 1.2 & 1.6 & 2.1 & 1.3 \\
5 & EC-EARTH/RACMO22E & 2.7 & 2.2 & 4.0 & 2.1 & 2.6 \\
6 & EC-EARTH/HIRHAM5 & 0.6 & 1.0 & 0.7 & 0.6 & 0.8 \\
7 & IPSL-CM5A-MR/RCA4 & 1.0 & 1.2 & 1.8 & 1.6 & 0.8 \\
8 & MPI-ESM-LR/CCLM4-8-17 & 0.8 & 1.0 & 1.2 & 0.7 & 0.8 \\
9 & MPI-ESM-LR/RCA4 & 0.8 & 1.5 & 1.0 & 0.9 & 0.9 \\
\hline Ens. mean* & All & 1.1 & 1.3 & 1.5 & 1.3 & 1.1 \\
Ens. SD* & All & 0.7 & 0.4 & 1.1 & 0.7 & 0.6 \\
\hline
\end{tabular}

* Ens. stands for ensemble, SD for standard deviation.

wet biases in summer and winter, which were 45.2 and $11.7 \mathrm{~mm} \mathrm{month}^{-1}$, respectively, compared to the transition seasons with relatively low biases $\left(7 \mathrm{~mm} \mathrm{month}{ }^{-1}\right.$ for spring and $8.5 \mathrm{~mm} \mathrm{month}^{-1}$ for autumn). The highest discrepancy of the models was obtained in mountainous areas located in the south (negative bias range of -75 to $-100 \mathrm{~mm} \mathrm{month}^{-1}$ ) and the eastern part of the region, with a negative bias in the range of -50 to $-75 \mathrm{~mm}$ month $^{-1}$. Obviously, the RMSEs from the bias-adjusted results were very low compared to those obtained from the raw simulations and were mostly close to zero for annual and seasonal means - apart from

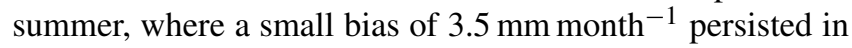
the adjusted precipitation. For maximum temperature, there was an overall cold bias for all seasons except for summer, which showed a warm bias everywhere, except for the mountains located in the south exhibiting a more enhanced cold bias. The annual RMSE of the raw data was $1.5^{\circ} \mathrm{C}$. Seasonal evaluations showed higher cold biases for winter and spring of 2.4 and $2.8^{\circ} \mathrm{C}$, respectively. For the corrected results, the bias was reduced to almost zero for all seasons and on an annual scale. For daily minimum temperature, the RMSE was slightly lower than for maximum temperature for all seasons except summer, where a relatively high warm bias of about of $2.3^{\circ} \mathrm{C}$ was found, which was additionally influenced by mountains located in the south. However, the spatial distribution of the biases showed a similar pattern to that discussed earlier for maximum temperature. Obviously, the RMSEs based on corrected datasets were all close to zero for both daily minimum and maximum temperatures. However, there was still a spatial structure to the errors. Biases were also removed in corrected precipitation - apart from summer precipitation, where small biases lower than $10 \%$ remained for all simulations (Sect. 2 in the Supplement). 

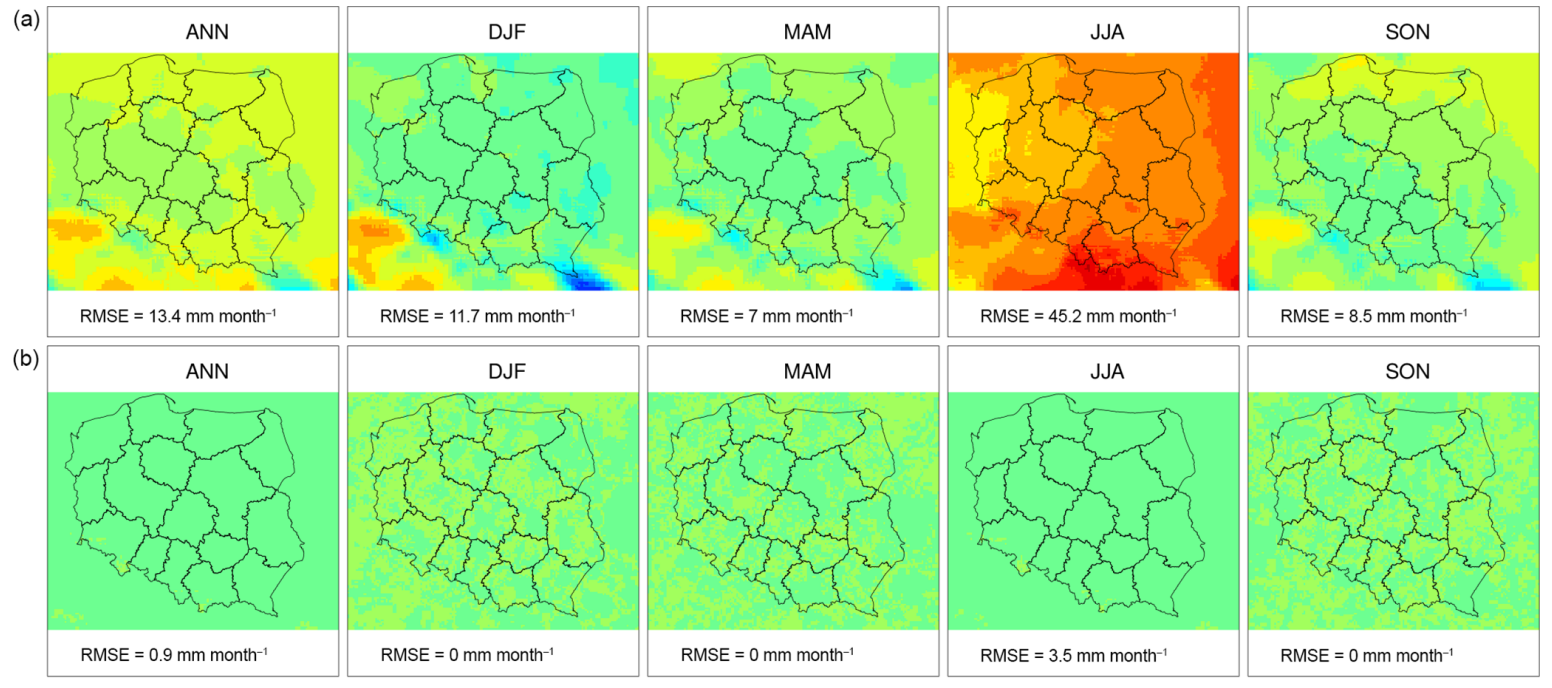

Precipitation bias [mm month-1] $\mid \begin{array}{ll}\text { (a) : Raw | } & \text { (b): Bias-corrected (METNO-QMAP-ChasePIObs-1951-2013) }\end{array}$

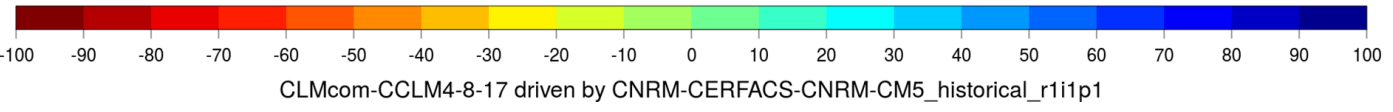

Figure 1. Bias evaluation for Simulation 1 (Table 1). The maps show RMSEs estimated on the difference between historical simulations (all available years included) and observations (CPLFD-GDPT5) for both raw (a) and bias-adjusted (b) monthly sums of precipitation modelled by the CCLM4-8-17 RCM driven by the CNRM-CM5 GCM. The legend "RMSE" indicates the areal mean bias estimated from the gridded annual and seasonal aggregates and the black polylines show the delimitation of the Polish provinces.

(a)

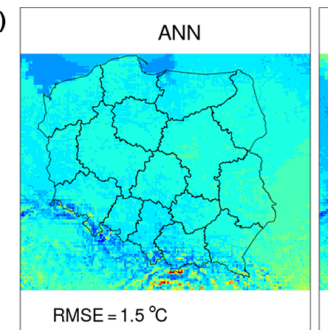

(b)

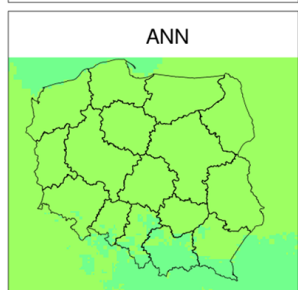

RMSE $=0{ }^{\circ} \mathrm{C}$

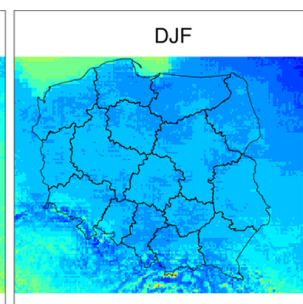

RMSE $=2.4^{\circ} \mathrm{C}$

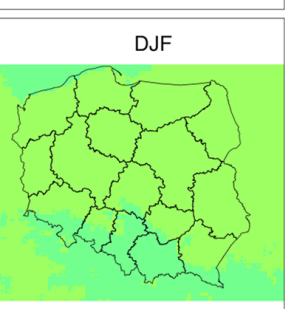

RMSE $=0^{\circ} \mathrm{C}$
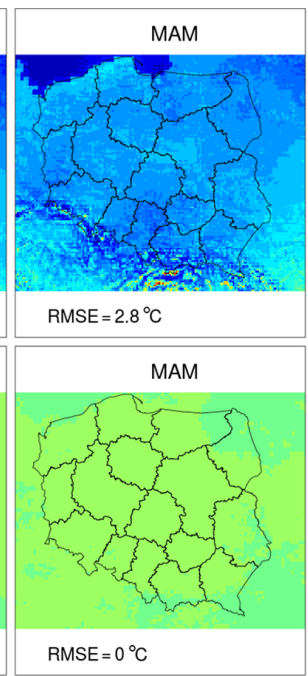

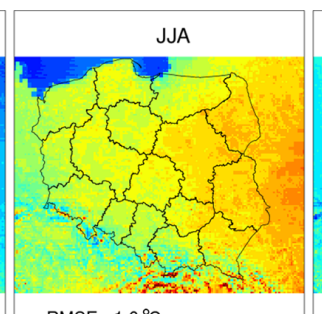

$\operatorname{RMSE}=1.6^{\circ} \mathrm{C}$

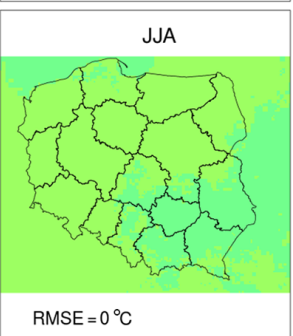

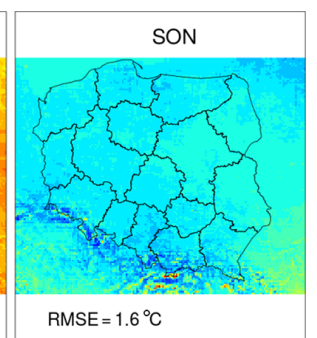

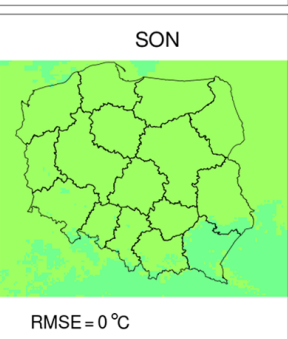

Max. daily temperature bias $\left[{ }^{\circ} \mathrm{C}\right] \mid$ (a) : Raw $\mid \quad$ (b): Bias-corrected (METNO-QMAP-ChasePIObs-1951-2013)

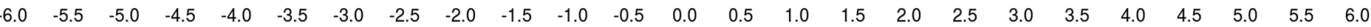

CLMcom-CCLM4-8-17 driven by CNRM-CERFACS-CNRM-CM5_historical_r1i1p1

Figure 2. As Fig. 1 but for daily maximum temperature.

\subsection{Sensitivity to the climate change signal}

Although the bias correction significantly improved the quality of the simulations in the trained control time period, it may alter the physical link between climate variables in the model (Ehret et al., 2012) and possibly modify the climate change signal (Teng et al., 2015). We further investigated the influence of QM on the climate change signal. Accordingly, we mapped the climate change signal in both raw and corrected simulations and focused on the time period 
(a)

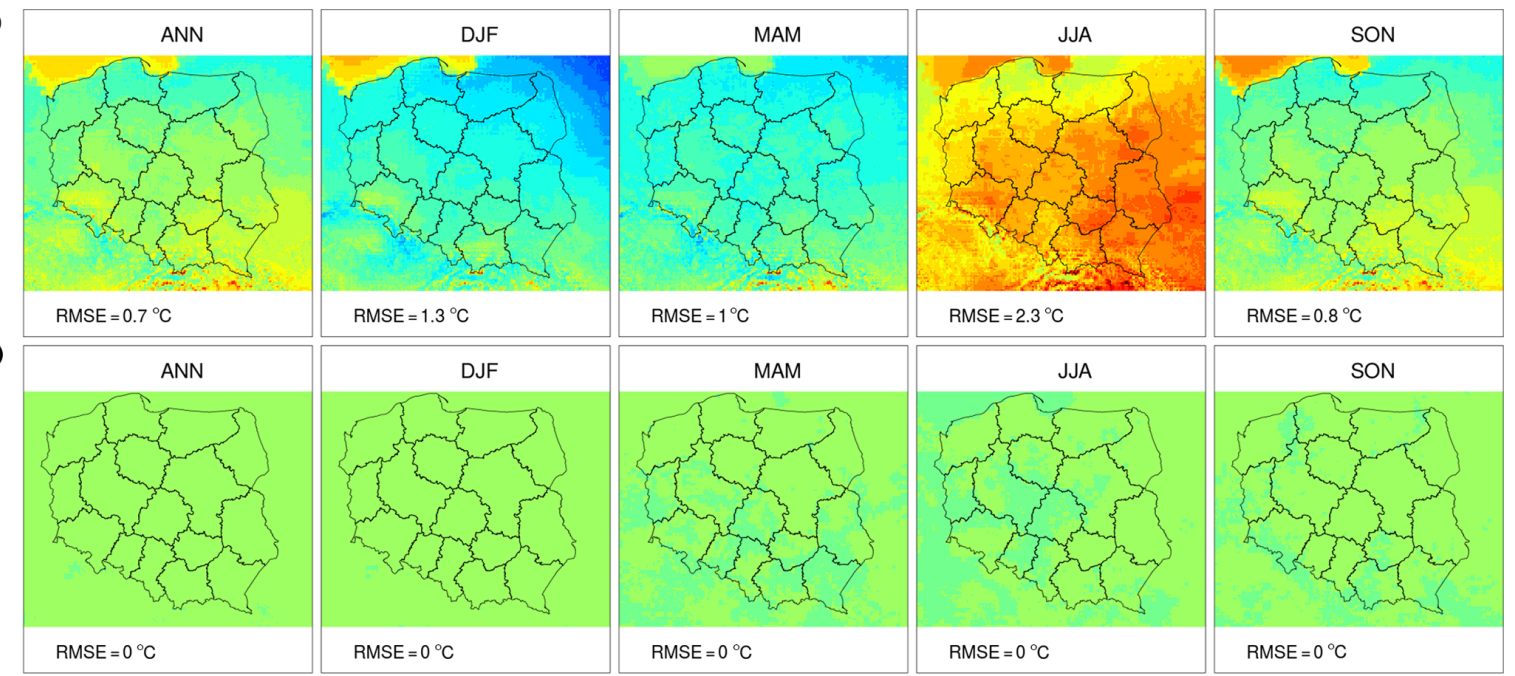

$\begin{array}{lll}\text { Min. daily temperature blas [C] | (a): Raw | } & \text { (b): Blas-corrected (METNO-QMAP-ChasePIObs-1951-2013) }\end{array}$

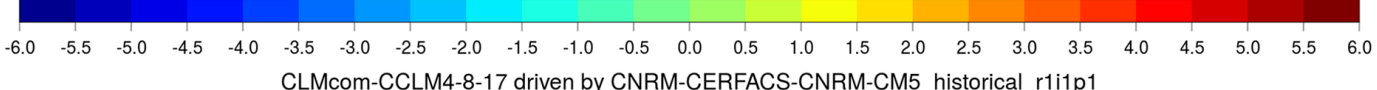

CLMCom-CCLM4-8-17 driven by CNRM-CERFACS-CNRM-CM5_historical_r1i1p1

Figure 3. As Fig. 1 but for daily minimum temperature.

2096-2100 with regard to historical data as we would expect a stronger alteration of the climate signal by the end of the century rather than earlier. An example of results based on the RCM RCA4 driven by the GCM MPI-ESM-LR is illustrated in what follows (Simulation 9 in Table 1). Figures 4-6 suggest that the sign and magnitude and the spatial distribution of the estimated changes were maintained and hence were not affected by the correction procedure. This demonstrated the reliability of the projected climate changes by the corrected RCM simulations. One possible explanation could be related to the use of the long reference record (1951-2013) on which the calibration was performed - i.e. the training distribution has been built on a long record encompassing different climate conditions rather than the short reference periods that are commonly selected (e.g. 19712000 or the new normal, 1981-2010). However, a few exceptions were found. For instance, the magnitude of the climate change (in root mean square terms) between historical and future (2096-2100) simulations for bias-adjusted modelled precipitation was reduced by approximately 15 to $25 \%$ in corrected summer and spring changes compared to corresponding changes in the raw data, respectively, although Hagemann et al. (2005) reported that the impact of the bias correction on the climate change signal may be larger than the signal itself. Overall, the spatial distribution of the climate change signal was, however, consistent in all corrected simulations - i.e. no random effect was introduced by the correction. Similar results were obtained for the other RCM simulations and even when assuming the RCP8.5 scenario (Figs. S28-S54).

\section{Projected future climate changes in Poland}

The dynamical downscaling performed here involved biasadjusted RCM simulations taken from the EURO-CORDEX experiment and corrected against the gridded daily dataset CPLFD-GDPT5 (Berezowski et al., 2016). From these datasets, we calculated climatic changes expressed in terms of relative changes in monthly sums of precipitation (in \%) and absolute changes in mean temperature (in ${ }^{\circ} \mathrm{C}$ ) with respect to the control period (1971-2000). The mean temperature values were calculated as the average between minimum and maximum temperature values. Although the projections cover small parts lying outside Poland, the maps presented here show only changes over the Polish territory.

We followed a twofold assessment procedure. First, we evaluated the multi-model ensemble means in projecting changes in annual and seasonal means of monthly sums of precipitation and daily means of temperature (Figs. 7 and 8). Second, we focused on projected changes in annual and seasonal means of monthly sums of precipitation and daily minimum and maximum temperatures taken from individual model simulations.

\subsection{Changes in the multi-model ensemble mean}

\subsubsection{Projected temperature changes}

Results suggest an ubiquitous warming over Poland in the future (Table 5a). Assuming the RCP4.5 scenario, the annual mean temperature over Poland is expected to increase by approximately $1^{\circ} \mathrm{C}$ for the period $2021-2050$ and by $2{ }^{\circ} \mathrm{C}$ for the period 2071-2100, respectively, with very low spa- 
(a)
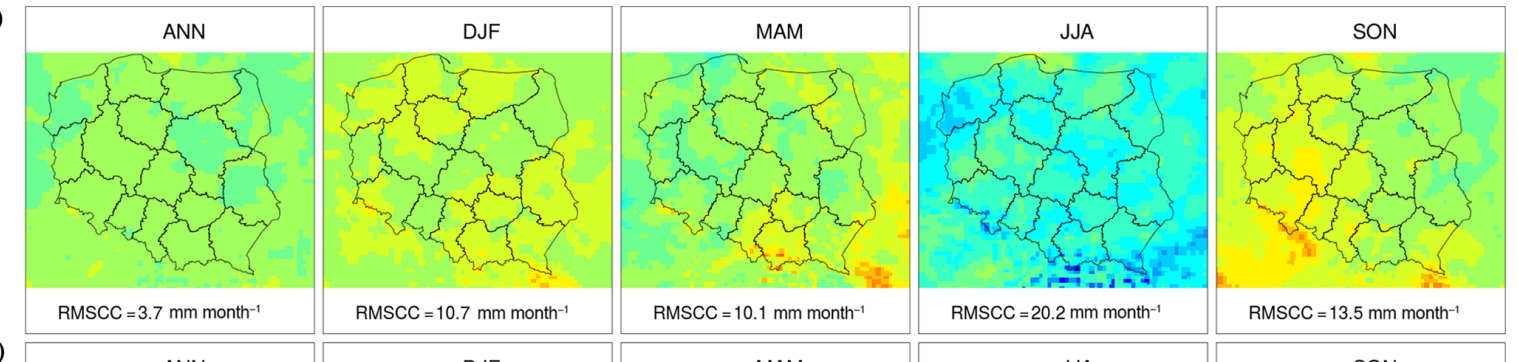

(b)
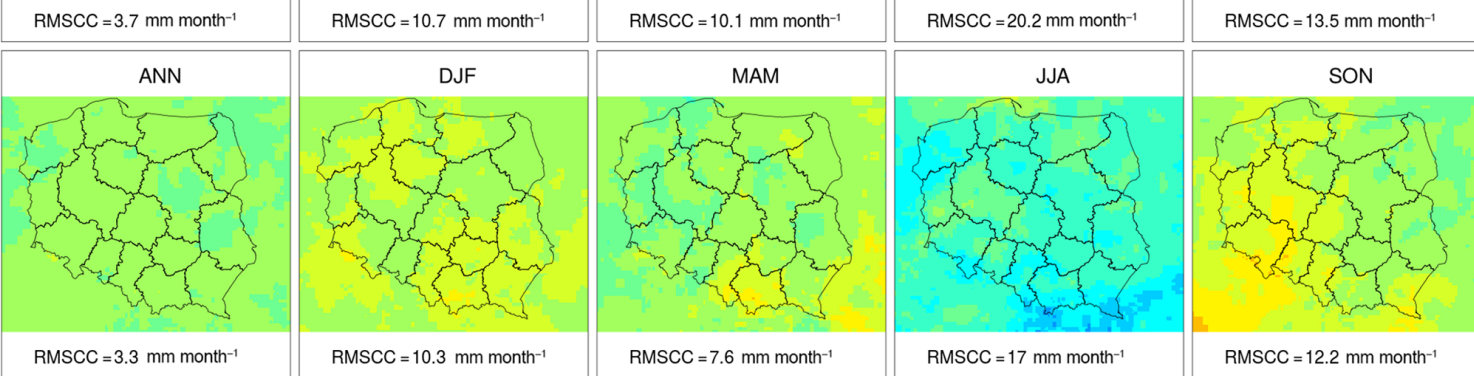

Precipitation change (2096-2100 w.r.t. hist) [mm/month] | (a) : Raw |

(b): Bias-corrected (METNO-QMAP-ChasePIObs-1951-2013)

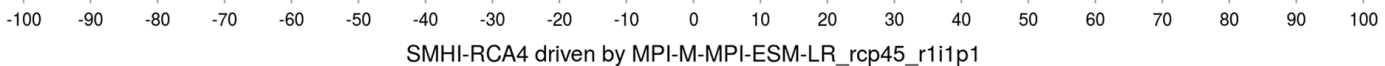

Figure 4. Precipitation change signal (mm month ${ }^{-1}$ ) for Simulation 9 (Table 1). The maps show absolute changes in the future (2096-2100) with regard to historical simulations (all years included) for both raw (a) and bias-adjusted (b) monthly sums of precipitation modelled by the RCA4 RCM driven by the MPI-ESM-LR GCM. The legend "RMSCC" indicates the areal mean change estimated from the gridded annual and seasonal aggregates and the black polylines show the delimitation of the Polish provinces.

(a)

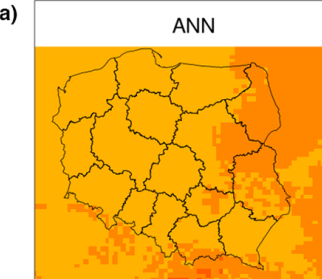

(b)

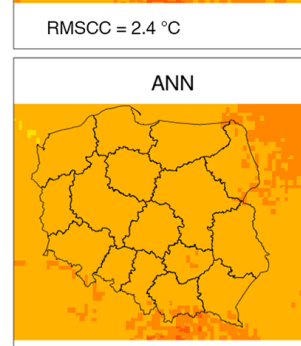

RMSCC $=2.3^{\circ} \mathrm{C}$

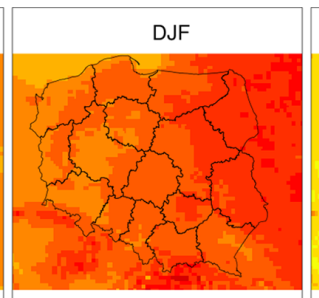

$\mathrm{RMSCC}=3.3^{\circ} \mathrm{C}$

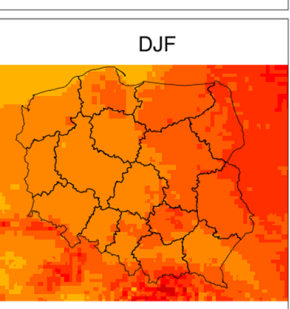

$\mathrm{RMSCC}=3.1^{\circ} \mathrm{C}$

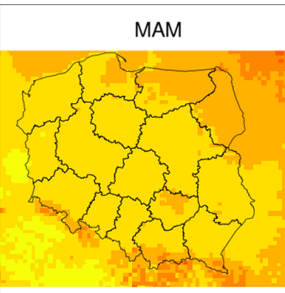

$\mathrm{RMSCC}=1.9^{\circ} \mathrm{C}$

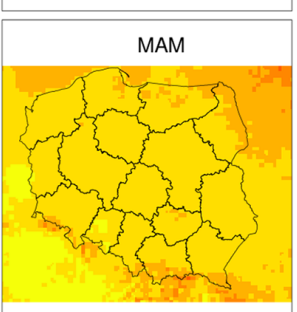

RMSCC $=1.8^{\circ} \mathrm{C}$

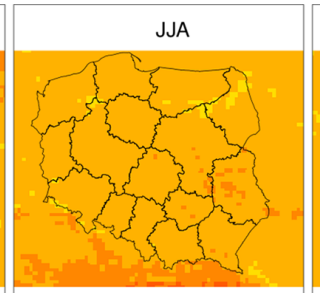

$\mathrm{RMSCC}=2.3^{\circ} \mathrm{C}$

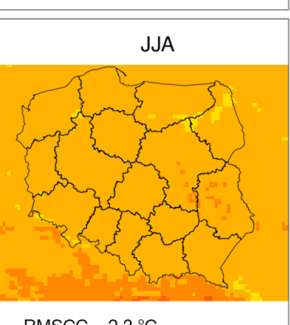

$\mathrm{RMSCC}=2.3^{\circ} \mathrm{C}$

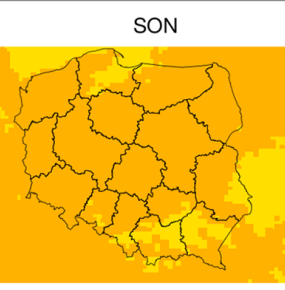

RMSCC $=2.1^{\circ} \mathrm{C}$

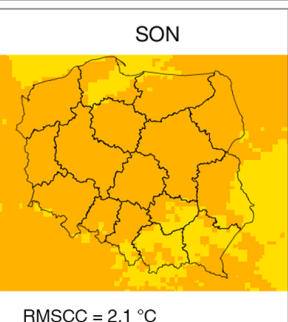

RMSCC $=2.1^{\circ} \mathrm{C}$

Min. daily temperature change (2096-2100 w.r.t. hist) [C] | (a) : Raw | $\quad$ (b): Bias-corrected (METNO-QMAP-ChasePIObs-1951-2013)

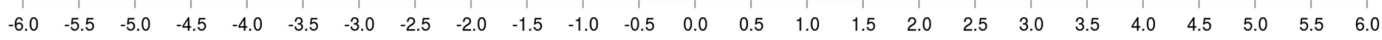

SMHI-RCA4 driven by MPI-M-MPI-ESM-LR_rcp45_r1i1p1

Figure 5. As Fig. 4 but for absolute changes in daily minimum temperature $\left({ }^{\circ} \mathrm{C}\right)$.

tial variability (the spatial SD is about $0.2^{\circ} \mathrm{C}$; e.g. Fig. 7). On a seasonal basis, the highest change is expected to occur in winter $\left(1.2^{\circ} \mathrm{C}\right.$ by $2021-2050$ and $2.5^{\circ} \mathrm{C}$ by $2071-$ 2100), followed by spring $\left(1^{\circ} \mathrm{C}\right.$ by $2021-2050$ and $2^{\circ} \mathrm{C}$ by 2071-2100) and autumn $\left(1.1^{\circ} \mathrm{C}\right.$ by $2021-2050$ and $1.8^{\circ} \mathrm{C}$ by
2071-2100), and the lowest in summer $\left(1^{\circ} \mathrm{C}\right.$ by $2021-2050$ and $1.7^{\circ} \mathrm{C}$ by $\left.2071-2100\right)$. Similarly to the changes in annual means of mean temperature, the seasonal changes also exhibit low spatial variability with a span of approximately $0.1^{\circ} \mathrm{C}$ (see also Supplement Sect. 4.1). 

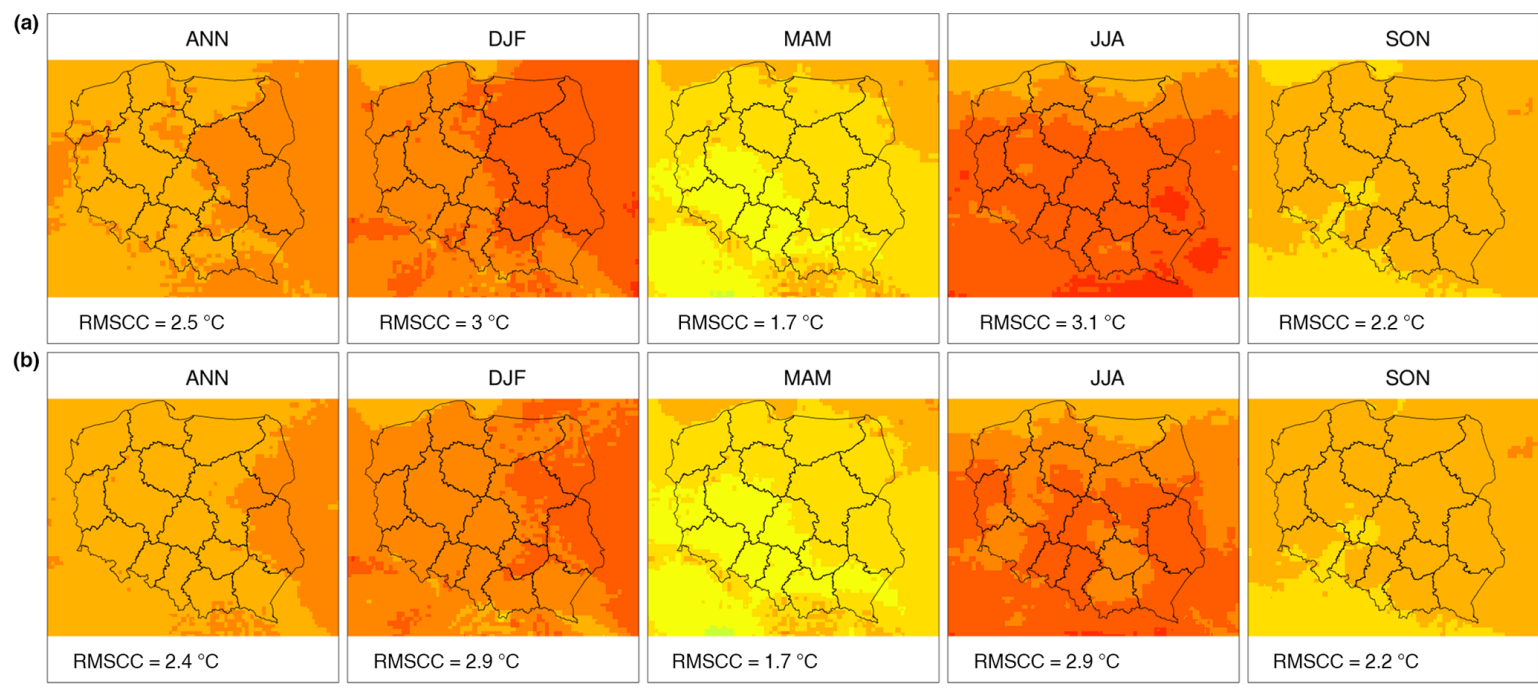

Min. daily temperature change (2096-2100 w.r.t. hist) [C] | (a) : Raw |

(b) : Bias-corrected (METNO-QMAP-ChasePIObs-1951-2013)

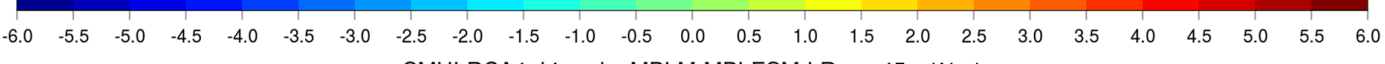

SMHI-RCA4 driven by MPI-M-MPI-ESM-LR_rcp45_r1i1p1

Figure 6. As Fig. 4 but for absolute changes in daily maximum temperature $\left({ }^{\circ} \mathrm{C}\right)$.

Table 5. Summary of changes in projected multi-model ensemble seasonal and annual regional means of mean temperature (a, in $\left.{ }^{\circ} \mathrm{C}\right)$ and precipitation (b, in \%) for the near (2021-2050) and far (2071-2100) futures assuming both the RCP4.5 and RCP8.5. Values in brackets indicate the 5th and 95th percentiles of the projected ensembles and hence represent the $90 \%$ confidence interval of the mean estimates from the multi-model ensemble.

\begin{tabular}{lccccc}
\hline Scenario/Horizon & DJF & MAM & JJA & SON & Annual \\
\hline & \multicolumn{5}{c}{ (a) Temperature changes } \\
\hline RCP4.5 by 2021-2050 & +1.2 & +1.0 & +1.0 & +1.1 & +1.1 \\
& {$[+0.3,+1.9]$} & {$[+0.6,+1.7]$} & {$[+0.7,+1.4]$} & {$[+0.6,+1.6]$} & {$[+0.7,+1.4]$} \\
RCP8.5 by 2021-2050 & +1.6 & +1.3 & +1.1 & +1.3 & +1.3 \\
& {$[+0.5,+2.5]$} & {$[+0.9,+2]$} & {$[+0.7,+1.3]$} & {$[+0.6,+1.8]$} & {$[+0.8,+1.8]$} \\
RCP4.5 by 2071-2100 & +2.5 & +2.0 & +1.7 & +1.8 & +2 \\
& {$[+1.1,+3.3]$} & {$[+1.1,+2.8]$} & {$[+1.3,+2.3]$} & {$[+1.4,+2.4]$} & {$[+1.4,+2.5]$} \\
RCP8.5 by 2071-2100 & +4.5 & +3.2 & +3.1 & +3.5 & +3.6 \\
& {$[+3.8,+5.3]$} & {$[+2.5,+4.0]$} & {$[+2.5,+3.9]$} & {$[+2.7,+4.2]$} & {$[+3.0,+4.1]$} \\
\hline & \multicolumn{5}{c}{ (b) Precipitation changes } \\
& +8.4 & +7.6 & +3.8 & +5.6 & \\
\hline RCP4.5 by 2021-2050 & $++2,+17]$ & {$[+2,+14]$} & {$[-2,+9]$} & {$[-2,+14]$} & {$[+4,+9]$} \\
& +13.2 & +10.5 & +4.7 & +6.8 & +8.0 \\
RCP8.5 by 2021-2050 & {$[+6,+22]$} & {$[+0.5,+22.9]$} & {$[+0.2,+11]$} & {$[+1,+15]$} & {$[+5,+11]$} \\
& +18.4 & +14.8 & +4.0 & +6.5 & +9.7 \\
RCP4.5 by 2071-2100 & {$[+12,+27]$} & {$[+7,+23]$} & {$[-7,+12]$} & {$[0,+12]$} & {$[+6,+13]$} \\
RCP8.5 by 2071-2100 & +26.8 & +26.4 & +5.2 & +13.1 & +15.7 \\
& {$[+18,+35]$} & {$[+16,+39]$} & {$[-5,+15]$} & {$[-1,+25]$} & {$[+9,+23]$} \\
\hline
\end{tabular}

The warming rate is accelerated when assuming the RCP8.5 emission scenario and when the far future time horizon is considered (Table 5a). As in the RCP4.5 scenario, the warming is expected to be highest during the winter season and the mean temperature is likely to be $4.5^{\circ} \mathrm{C}$ across the region, with a clear northeast to southwest gradient (Fig. 8). This is in line with Piotrowski and Jędruszkiewicz (2013), who found that this was mainly attributable to an increase in the frequency of cyclonic circulation types. In summer, the strongest warming is likely to occur in the mountainous re- 

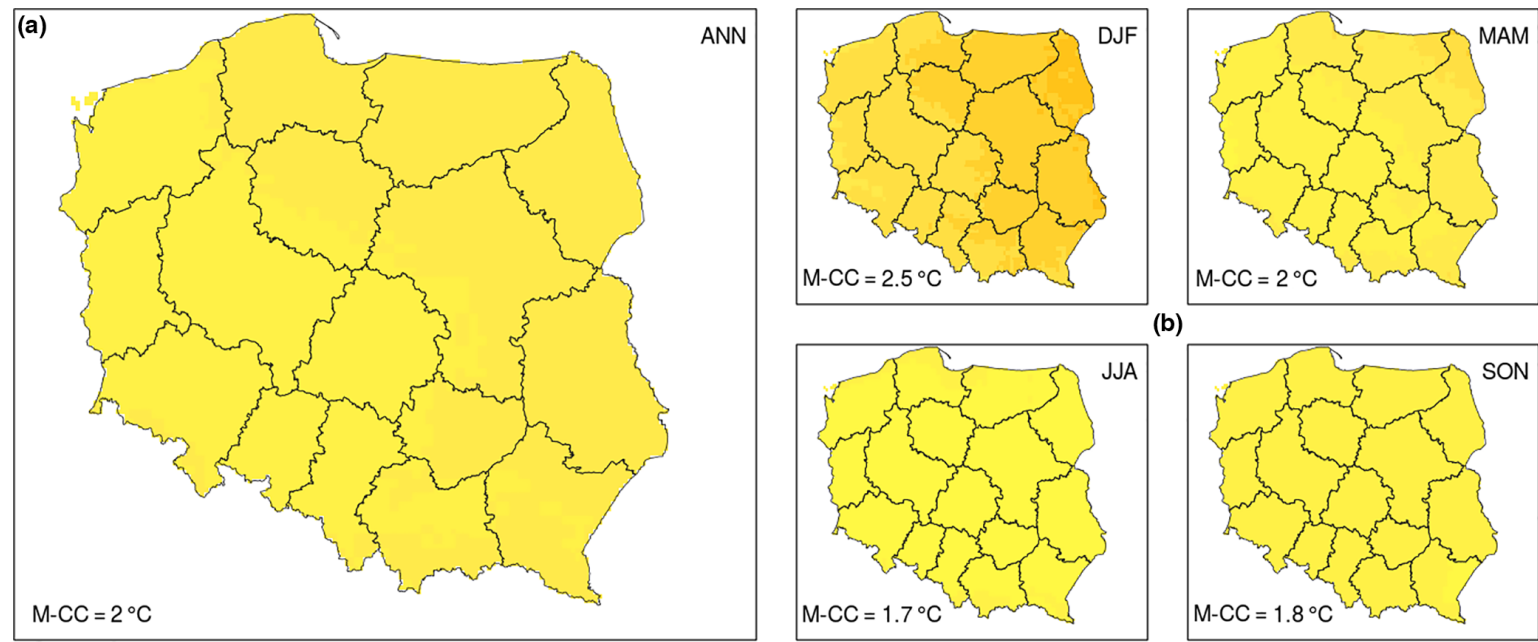

(b)
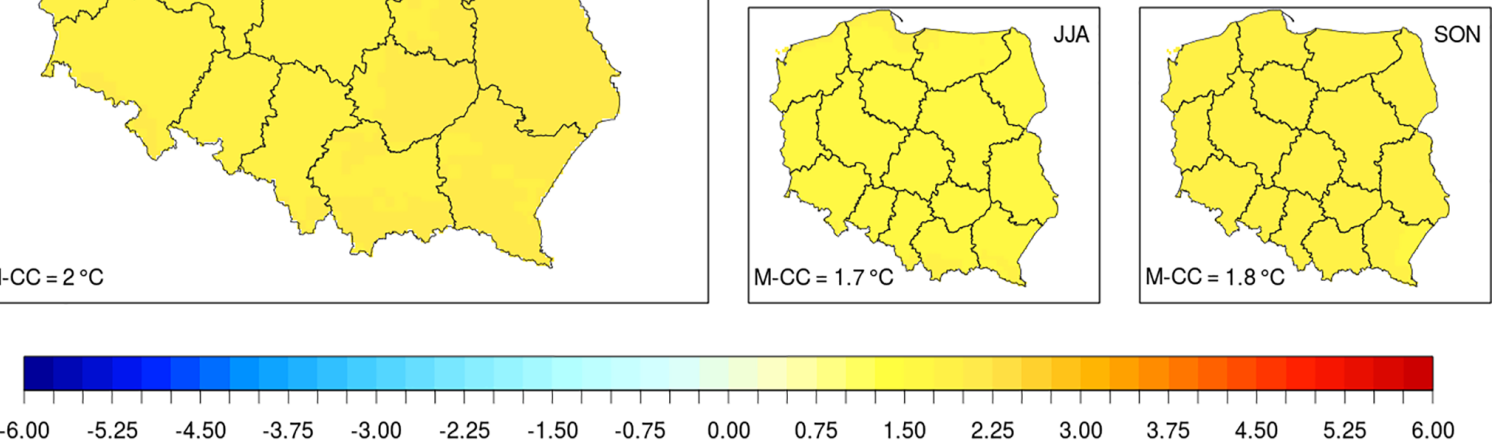

Ens. mean of absolute changes in mean temperature (2071-2100 w.r.t. $1971-2000)\left[{ }^{\circ} \mathrm{C}\right]$

Figure 7. Projected temperature changes $\left({ }^{\circ} \mathrm{C}\right)$ for the far future (2071-2100) assuming the RCP4.5 scenario. Maps show annual (a) and seasonal (b) changes in the multi-model ensemble mean of absolute temperature with regard to the control period (1971-2000). The legend "M-CC" means the areal mean change estimated from the gridded data.
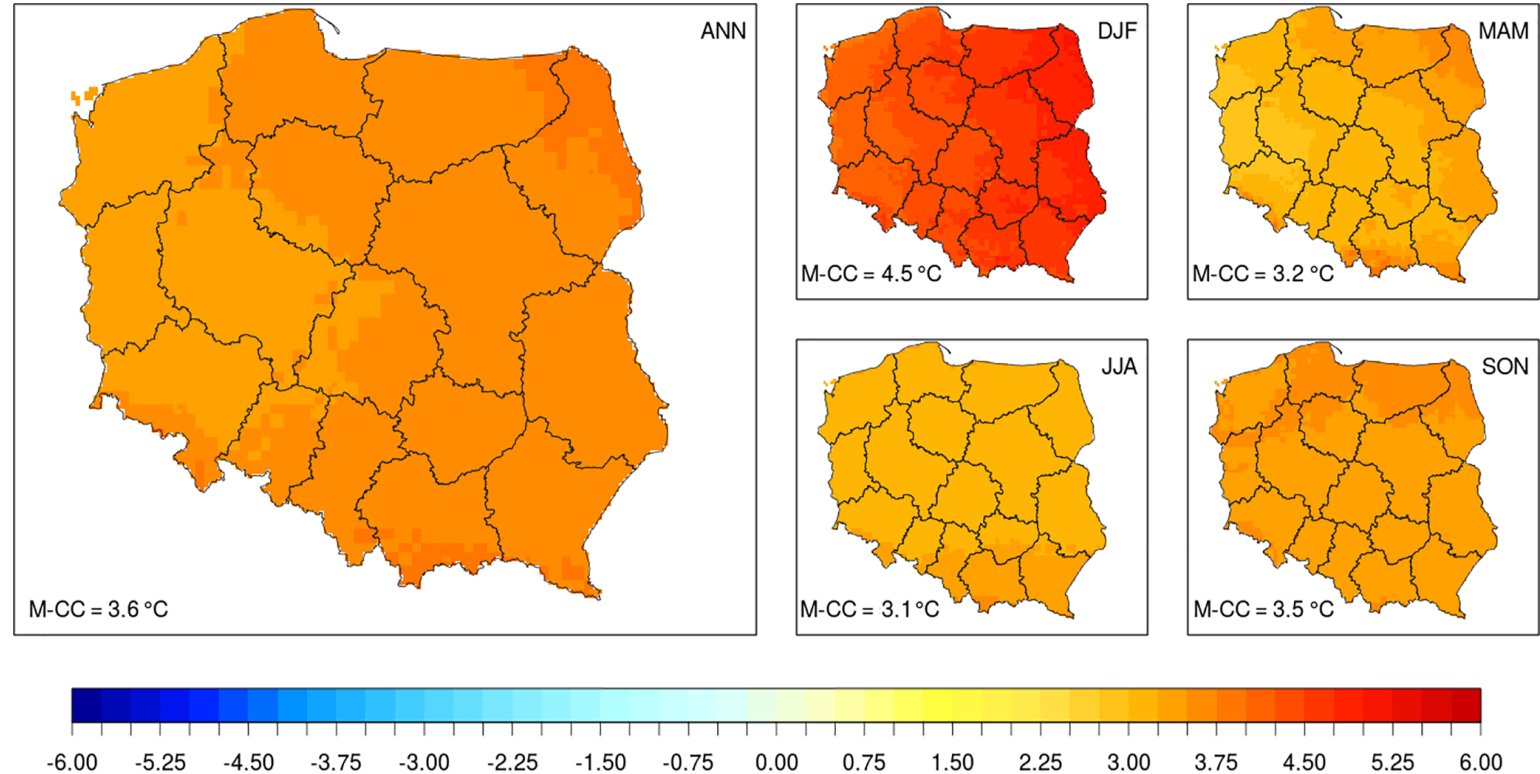

Ens. mean of absolute changes in mean temperature (2071-2100 w.r.t. $1971-2000)\left[{ }^{\circ} \mathrm{C}\right]$

Figure 8. As Fig. 7 but for projected temperature changes $\left({ }^{\circ} \mathrm{C}\right)$ in the far future (2071-2100) assuming the RCP8.5 scenario.

gions in the south, where temperatures are expected to rise by as much as $3^{\circ} \mathrm{C}$ by $2071-2100$.

\subsubsection{Projected precipitation changes}

Projections show that Poland is expected to get more precipitation in the future in all seasons (Table 5b). In general, the projections based on the two scenarios show similar changes for the near future. But for the far future, the RCP8.5 highemission scenario projects a significantly stronger increase.

Assuming the intermediate emission scenario RCP4.5, the expected annual mean precipitation increase (averaged over Poland) is approximately $6 \%$ by the near future (2021-2050) 

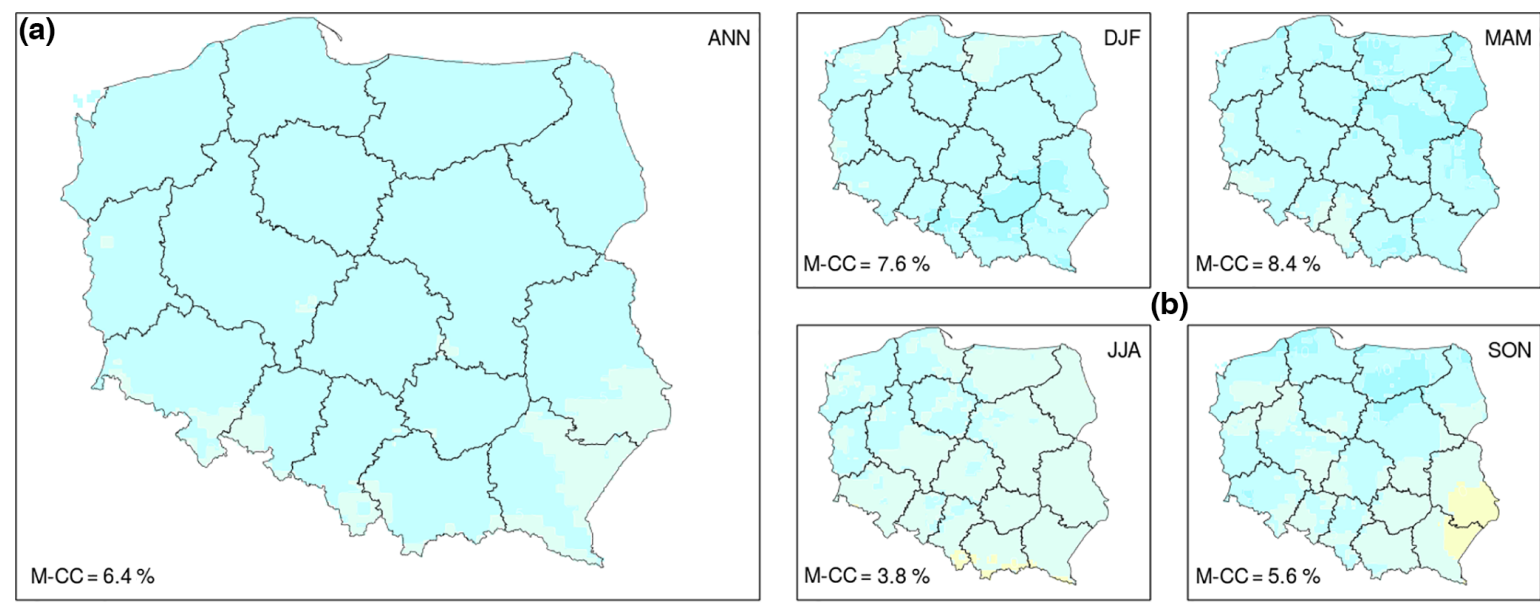

(b)
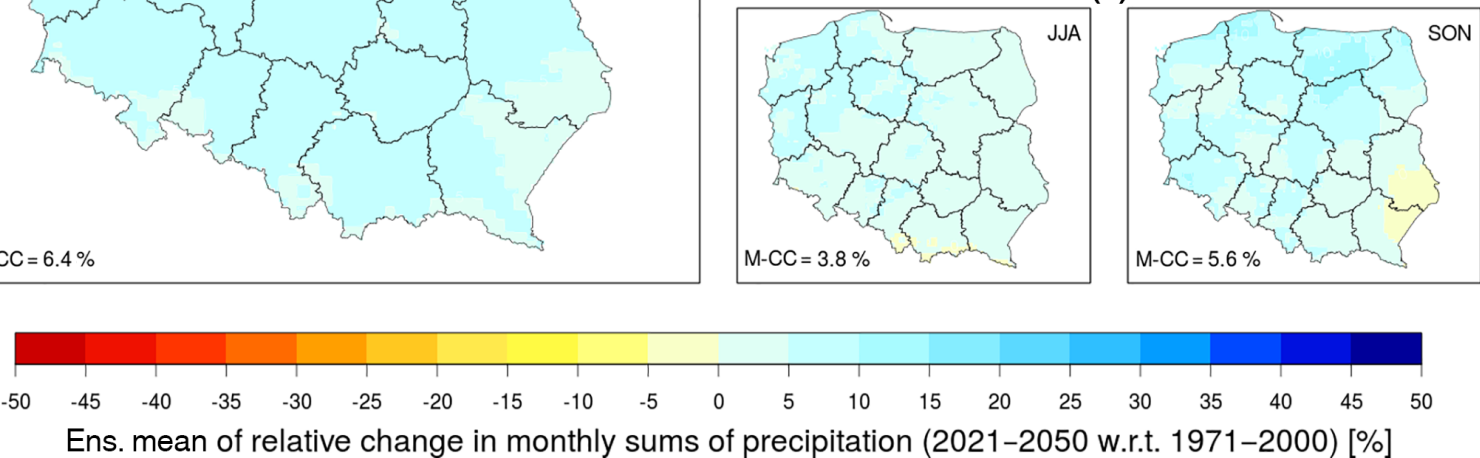

Figure 9. Projected changes in monthly sums of precipitation (\%) for the period (2021-2050) assuming the RCP4.5 scenario. Maps show annual (a) and seasonal (b) changes in the multi-model ensemble mean of absolute temperature with regard to the control period (1971-2000). The legend "M-CC" means the areal mean change estimated from the gridded data.

and $10 \%$ by the far future (2071-2100). On a seasonal basis, the highest rates are expected to occur in winter $(+8 \%$ by $2021-2050$ and $+18 \%$ by $2071-2100)$ and spring ( $+8 \%$ by 2021-2050 and $+15 \%$ by 2071-2100), while the smallest changes are expected to occur in summer $(+4 \%$ for both future time periods) and autumn ( +6 to $+7 \%$, regardless of the future period). Those projected changes are in line with Romanowicz et al. (2016), who found a precipitation increase of up to $15 \%$ considering only 10 small catchments spread across the country (not for all of Poland).

Assuming the RCP8.5 scenario, the expected change by the far future (2071-2100) is approximately $+16 \%$ for the annual mean precipitation, with stronger increases in winter $(27 \%)$ and spring (26\%), and more moderate changes in summer $(+5 \%)$ and autumn $(+13 \%)$. Summer exhibits similar changes in precipitation regardless of emission scenario and time horizon.

In contrast to temperature, precipitation changes reveal higher variability in space (spatial SD averaged across all scenarios and periods equals $5 \%$ ). In southern Poland, north of the Carpathian Mountains, summer and autumn precipitation are even expected to decrease by as much as $5 \%$ (Fig. 9). The influenced area is more pronounced in projections for the far future (2071-2100) and when assuming the high-emission scenario RCP8.5 (Fig. 10).

\subsection{Changes in individual model simulations}

\subsubsection{Projected temperature changes}

Results based on bias-adjusted individual model simulations also show a systematic increase in both minimum and maximum temperatures for the two future periods and RCPs, respectively.

Assuming the RCP4.5 scenario, the absolute changes in annual means of daily minimum temperature by 2021-2050 vary between 0.8 and $1.6^{\circ} \mathrm{C}$ (Fig. S83). On a seasonal basis, the warming is more intensified in winter (Fig. 11), varying from $0.3{ }^{\circ} \mathrm{C}$ (CCLM4-8-17/MPI-ESM-LR) to $2.2{ }^{\circ} \mathrm{C}$ (HIRAM5/EC-EARTH), and slightly amplified in spring (Fig. S91), varying from 0.7 to $1.8^{\circ} \mathrm{C}$, respectively. Although changes in annual means of daily maximum temperature are expected to have similar magnitude, they are slightly less pronounced than for daily minimum temperature and vary from 0.6 to $1.4{ }^{\circ} \mathrm{C}$. The same tendency was found for seasonal means of maximum temperature, which exhibit a slightly amplified magnitude in autumn when compared to seasonal means of daily minimum temperature, and vary between 0.5 and $1.6^{\circ} \mathrm{C}$ (Fig. S119). The lowest increase is expected to occur in summer (Fig. S115) for both minimum and maximum temperatures by up to $1.6^{\circ} \mathrm{C}$ (Fig. S95) and $1.4^{\circ} \mathrm{C}$ (Fig. S115), respectively. Projected minimum temperatures to the end of the 21st century are also expected to increase for both annual (Fig. S84) and seasonal timescales (e.g. Fig. S88), and range from 1.4 to $2.6^{\circ} \mathrm{C}$. On a seasonal scale, this increase is amplified in winter and is expected to vary from 1.2 to $3.7^{\circ} \mathrm{C}$, followed by spring during which 

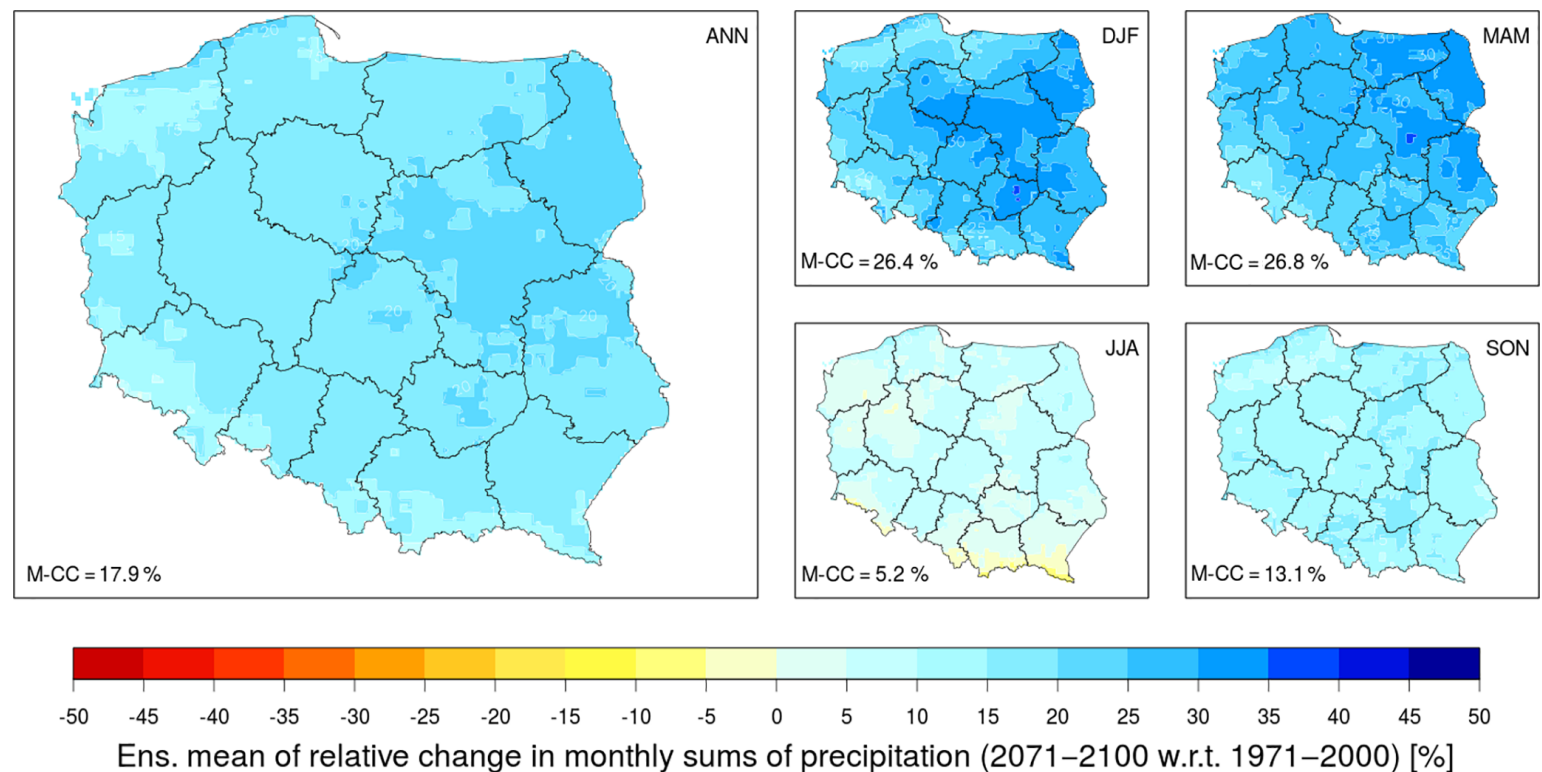

Figure 10. As Fig. 9 but for projected precipitation changes (\%) by 2071-2100 assuming RCP8.5 scenario.

the highest projected warming is expected to reach approximately $3{ }^{\circ} \mathrm{C}$. The autumn and summer means of daily minimum temperature show the same amplitude as the annual changes, and vary from 1.5 to $2.5^{\circ} \mathrm{C}$ and 1.4 to $2.5^{\circ} \mathrm{C}$, respectively. Likewise, the changes in seasonal means of maximum temperature range from 1.2 to $3.2^{\circ} \mathrm{C}$ in winter, from 0.9 to $2.9^{\circ} \mathrm{C}$ in spring, from 1.3 and $2.7^{\circ} \mathrm{C}$ in autumn, and from $1{ }^{\circ} \mathrm{C}$ to $2.4^{\circ} \mathrm{C}$ in summer (Supplement Sect. 4.2). Again, summer means of daily maximum temperature exhibit the lowest warming. Similarly to precipitation, both temperature variables show large differences between the simulations in projecting the magnitude of the seasonal changes. However, they all agree on the sign of the change (e.g. Fig. S104 and S112).

When assuming the RCP8.5 scenario, changes in annual means of minimum (Fig. S85) and maximum (Fig. S105) temperature show slightly higher increases by as much as 0.5 and $0.25^{\circ} \mathrm{C}$ in the near future time period, respectively, than what is expected when assuming the RCP4.5 scenario. These increases are expected to be more amplified by $2{ }^{\circ} \mathrm{C}$ by the end of the 21 st century (Fig. S86 and S106). The highest warming is expected to occur in winter means of daily minimum temperature with an increasing rate higher than $5{ }^{\circ} \mathrm{C}$ simulated by the RCA4 and CCLM4-8-17 RCMs, both driven by the CNRM-CM5 GCM (Fig. S90).

Piniewski et al. (2017a) assessed the robustness of the temperature change signal using the same set of RCM simulations and demonstrated that the increase obtained in the annual means of daily minimum and maximum temperature was robust. However, a lower robustness was found on the seasonal scale.

\subsubsection{Projected precipitation changes}

Assuming the RCP4.5 scenario, the changes in annual means of monthly sums of precipitation are projected to increase by 3 to $9 \%$ all over the country for the period 2021-2050. Although all simulations agree on the overall positive change, they disagree on the spatial distribution - although patches of slight decreases of less than $5 \%$ are expected and are partly located in mountainous areas (Fig. 12). The highest increase is simulated by the RACMO22E model driven by the EC-EARTH model in the east of the region. On a seasonal basis, different tendencies of climate change signal were found. For winter, although the overall picture of the changes suggested wetter conditions, models disagree on both the sign and magnitude of the corresponding change especially when the spatial distribution of the change is of interest. For instance, the CCLM4-8-17/CNRM-CM5 model show a dry pattern in the northeast, down by $10 \%$, and a wet pattern in the southwest, which is most pronounced in the mountainous areas, where the increase can reach up to $20 \%$ (Fig. S67). The tendency is reversed in winter precipitation modelled by the CCLM4-8-17/MPI-ESM-LR GCM, where a clear northwest to southeast gradient was found. The highest change was simulated by the RCM RCA4 driven by the EC-EARTH model, showing an overall increase of up to $13 \%$. For summer precipitation, the simulations show a disagreement in even the projected sign of the climate change signal, which ranged from -5 to $+9 \%$ (Fig. 13). Moreover, the RCA4/MPI-ESM-LR simulation exhibits a dry pattern in southern parts of the country including the mountainous areas, which can be down by $20 \%$, whereas the RACMO22E/EC-EARTH simulation shows the opposite tendency, although the northwest to southeast gra- 

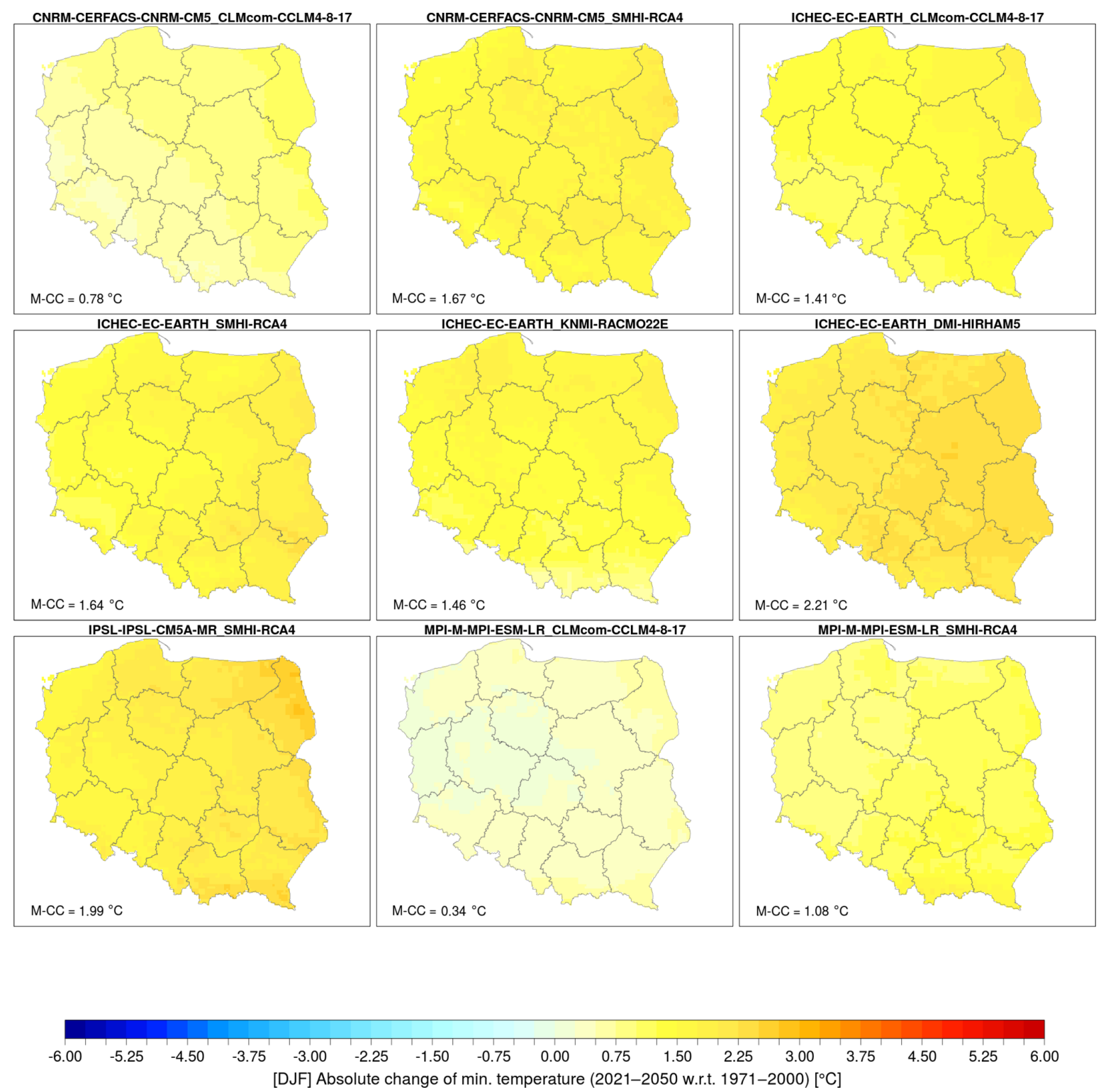

Figure 11. Changes in projected winter means of daily minimum temperature by 2021-2050 assuming the RCP4.5 scenario. The maps show the absolute changes with regard to the historical period (1971-2000) for all nine adjusted simulations.

dient is reproduced. For the spring season (Fig. S71), there is a dominance of mostly wet patterns, where precipitation changes vary from $+1 \%$ (CCLM4-8-17/CNRM-CM5 simulation) to $+17 \%$ (CCLM4-8-7/MPI-ESM-LR simulation). Similarly, autumn precipitation changes are expected to vary between -4 and $13 \%$ and show similar patterns to those obtained for winter. Hence, no agreement between the corrected simulations was seen for the near future (Fig. S79). The direction of the change signal becomes clearer towards the end of the century, showing overall wetter conditions on an annual scale, and the projected changes are expected to vary from $4 \%$ (RCA4/MPI-ESM-LR simulation) to $13 \%$ (RCA4/CNRM-CM5 simulation) (Fig. SM 60). Surprisingly, when considering the far future, simulations agree well on wetter conditions in winter and spring than those observed during the reference period (Fig. S68 and S72). The largest increase in annual means is then expected to be as much as $25 \%$ (CCLM4-8-17/EC-EARTH simulation) over all the region. However, changes in seasonal summer means of precipitation have been uncertain and are expected to vary by from -8 to $11 \%$ (Fig. S76). Even though disagreements between simulations dominate in autumn and summer, small differences are obtained for modelled summer precipitation when the RCM is driven by the MPI-ESM-LR global climate boundaries. In contrast, the highest changes are simulated by 


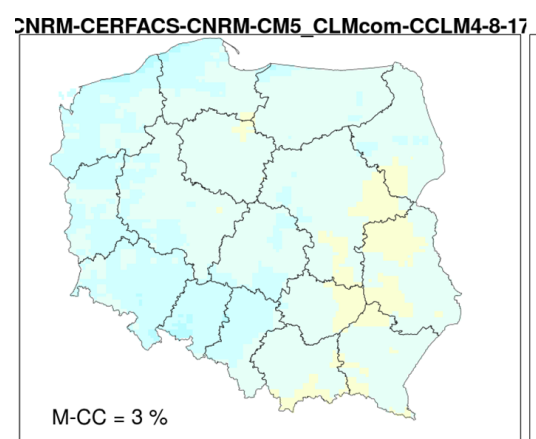

CNRM-CERFACS-CNRM-CM5_SMHI-RCA4

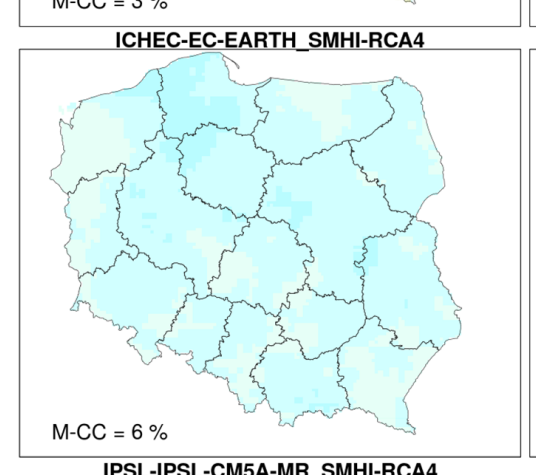

$\mathrm{M}-\mathrm{CC}=4 \%$
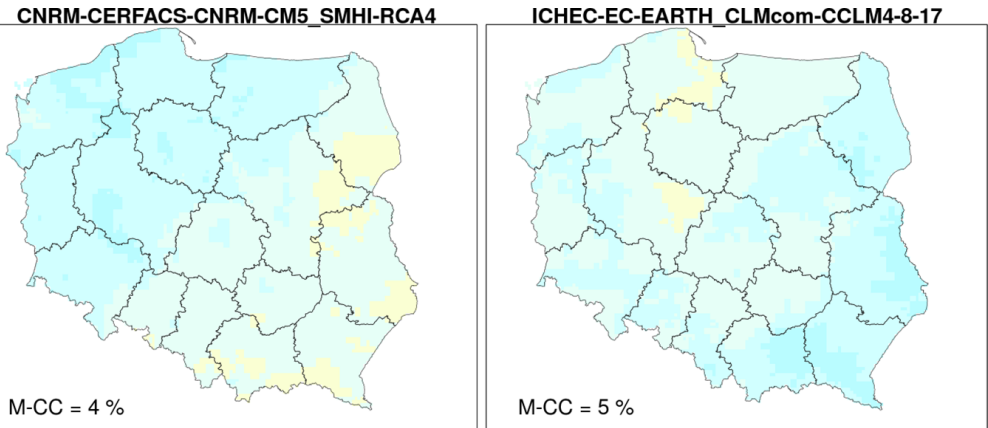

ICHEC-EC-EARTH KNMI-RACMO22E

ICHEC-EC-EARTH_DMI-HIRHAM5

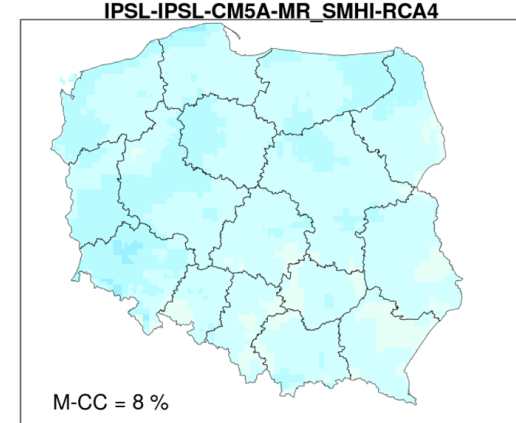

$\mathrm{M}-\mathrm{CC}=9 \%$

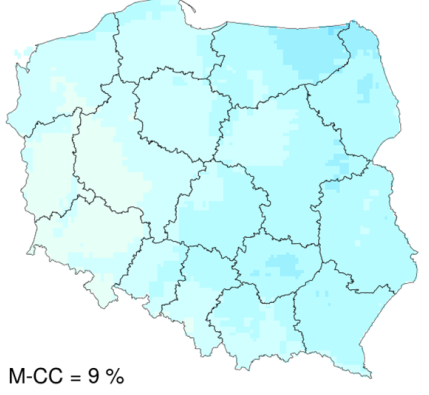

MPI-M-MPI-ESM-LR_CLMcom-CCLM4-8-17

$\mathrm{M}-\mathrm{CC}=4 \%$
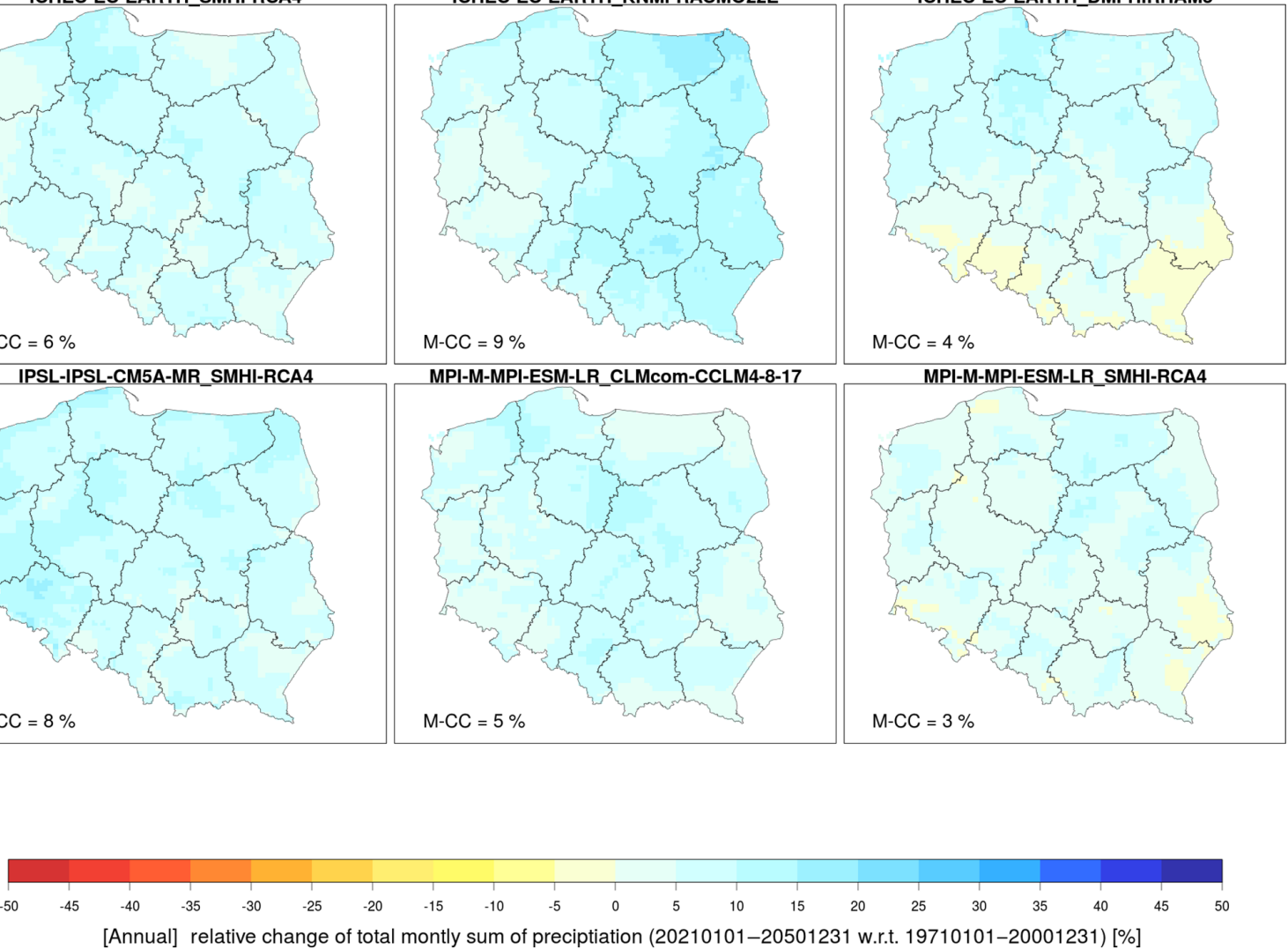

Figure 12. Changes in projected annual means of monthly sums of precipitation by 2021-2050 assuming the RCP4.5 scenario. The maps show relative changes with regard to the historical time period (1971-2000) for the nine bias-adjusted simulations.

the CCLM4-18-17 RCM driven by the EC-EARTH GCM, and they are more robust in spring than in winter.

Assuming the RCP8.5 scenario, the spatial distribution of the increase in the annual means of precipitation becomes more dominant, and results show rather good agreement between simulations on projected wetter conditions by as much as $22 \%$ (Fig. S65-S66), except for the HIRHAM5/ECEARTH simulation, which shows a decrease of less than $5 \%$ by the near future in southwestern areas (Fig. S65). In general, this amplification can be due to the increase in water vapour associated with warmer future climate conditions. The same annual tendency is reflected in winter and spring, but the magnitude of the change varies much between the simulations $(+14$ to $+41 \%)$. In summer and autumn, however, the disagreement in the projected climate change signal persists to the end of the century, during which wetter and drier conditions are likely to occur (Fig. 14). For instance, the RCA4 RCM driven by the EC-EARTH GCM projects a decrease in summer precipitation down to $6 \%$, whereas the CCLM4-8-17 RCM driven by the CNRM-CM5 GCM shows overall wet patterns and an increase of up to $15 \%$. The largest increase in winter is projected by the RACMO22E/EC-EARTH simulation (Fig. 15).

Piniewski et al. (2017a) assessed in a separate analysis the robustness of these projections and found that even though the models agreed well on a precipitation increase, 


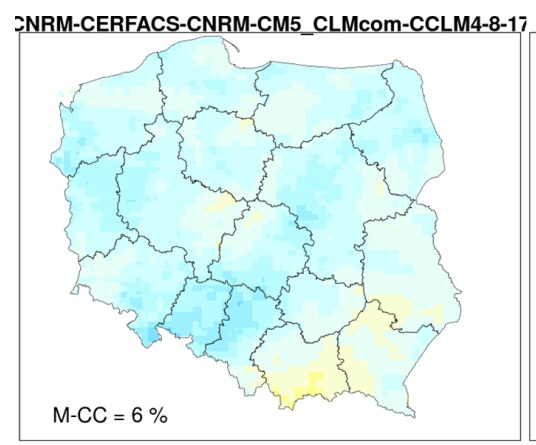

CNRM-CERFACS-CNRM-CM5_SMHI-RCA4 ICHEC-EC-EARTH_CLMcom-CCLM4-8-17

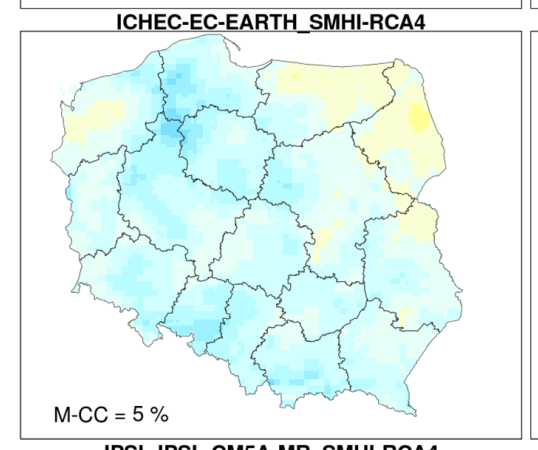

$\mathrm{M}-\mathrm{CC}=-1 \%$

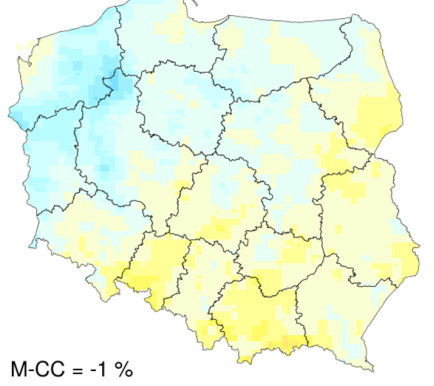

ICHEC-EC-EARTH_KNMI-RACMO22E

$\mathrm{M}-\mathrm{CC}=4 \%$
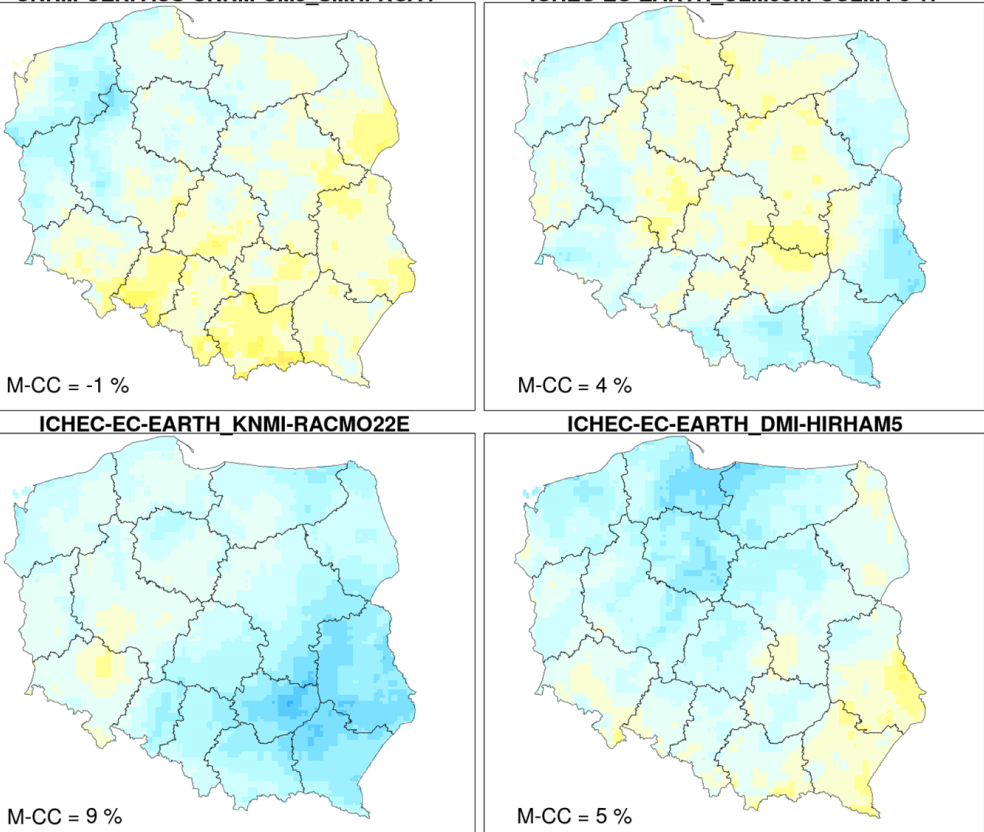

ICHEC-EC-EARTH_DMI-HIRHAM5

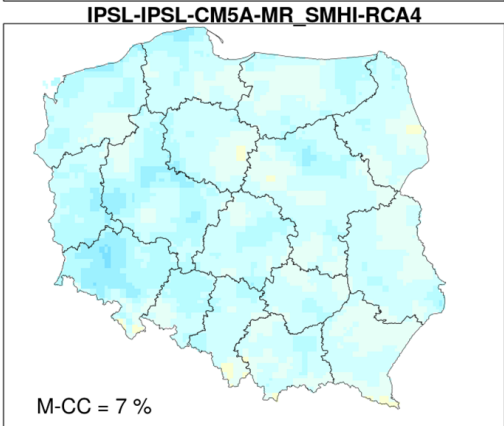

MPI-M-MPI-ESM-LR CLMcom-CCLM4-8-17

$\mathrm{M}-\mathrm{CC}=5 \%$
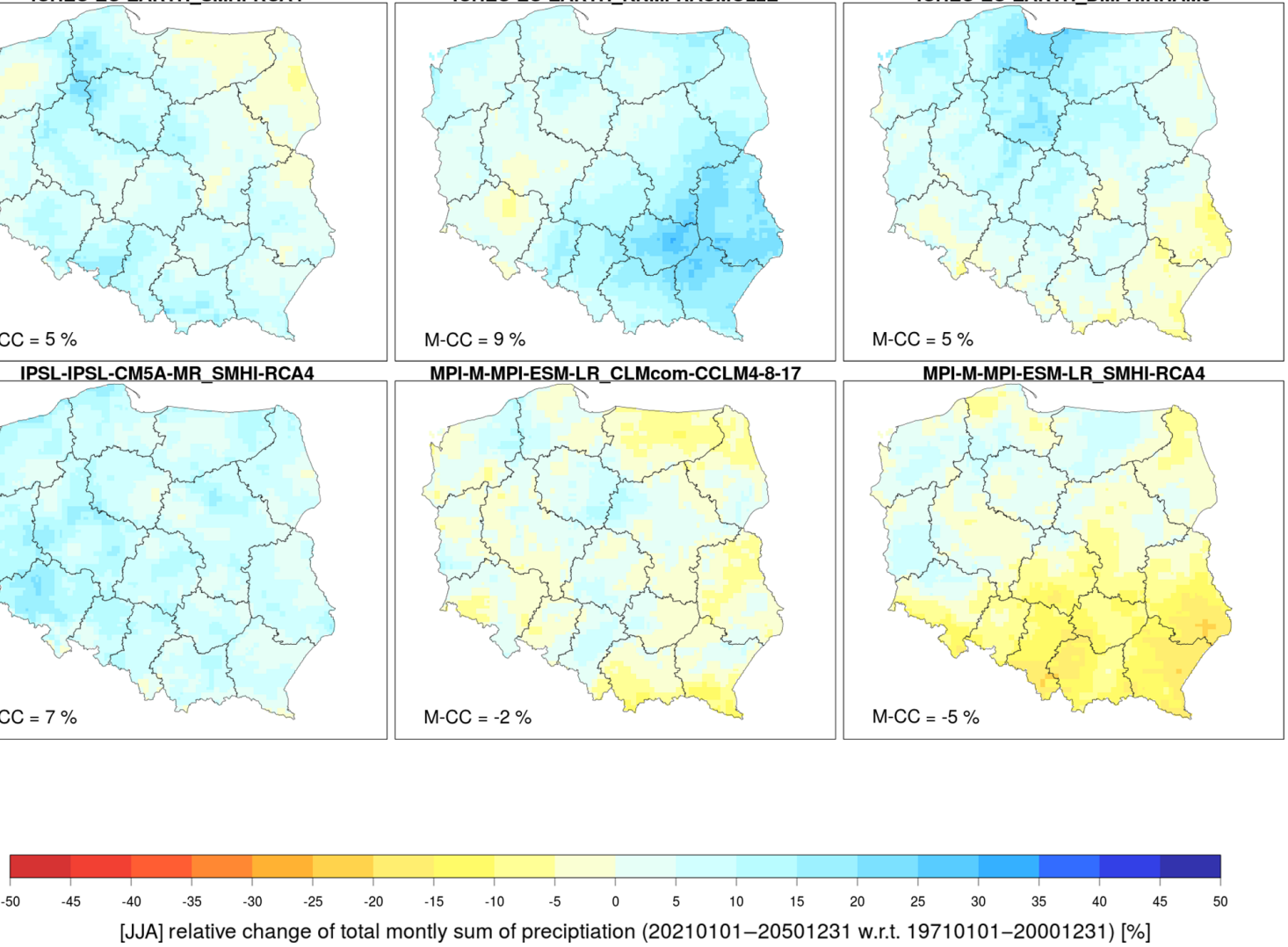

Figure 13. Changes in projected summer means of monthly sums of precipitation by 2021-2050 assuming the RCP4.5 scenario. The maps show the relative changes with regard to the historical period (1971-2000) for the nine adjusted simulations.

the changes were, in general, uncertain and not robust. They also pointed out that the spatial variability of the climate change signal was quite variable between individual climate model simulations, which considerably reduced the robustness, especially for the far future.

\section{Data availability}

The CHASE-PL Climate Projection (CPLCP) dataset produced here was made available for use in two different ways: (1) in a long-lasting research data repository and (2) through a dedicated CHASE-PL web geoportal. The first option (Sect. 5.1) is meant to serve mainly researchers, particularly users of environmental models to apply the bias-corrected high-resolution climate data as a consistent forcing dataset for projecting climate change impacts on different sectors in Poland. In this case, to achieve full consistency, it is recommended to use the observational (CPLFD-GDPT5) dataset (Berezowski et al., 2016), used as a reference for model calibration and validation. The second option (Sect. 5.2) is expected to serve both researchers and a wider audience, including students, stakeholders, and public authorities, as climate change science has not been disseminated widely in Poland to date (Kundzewicz and Matczak, 2012). 

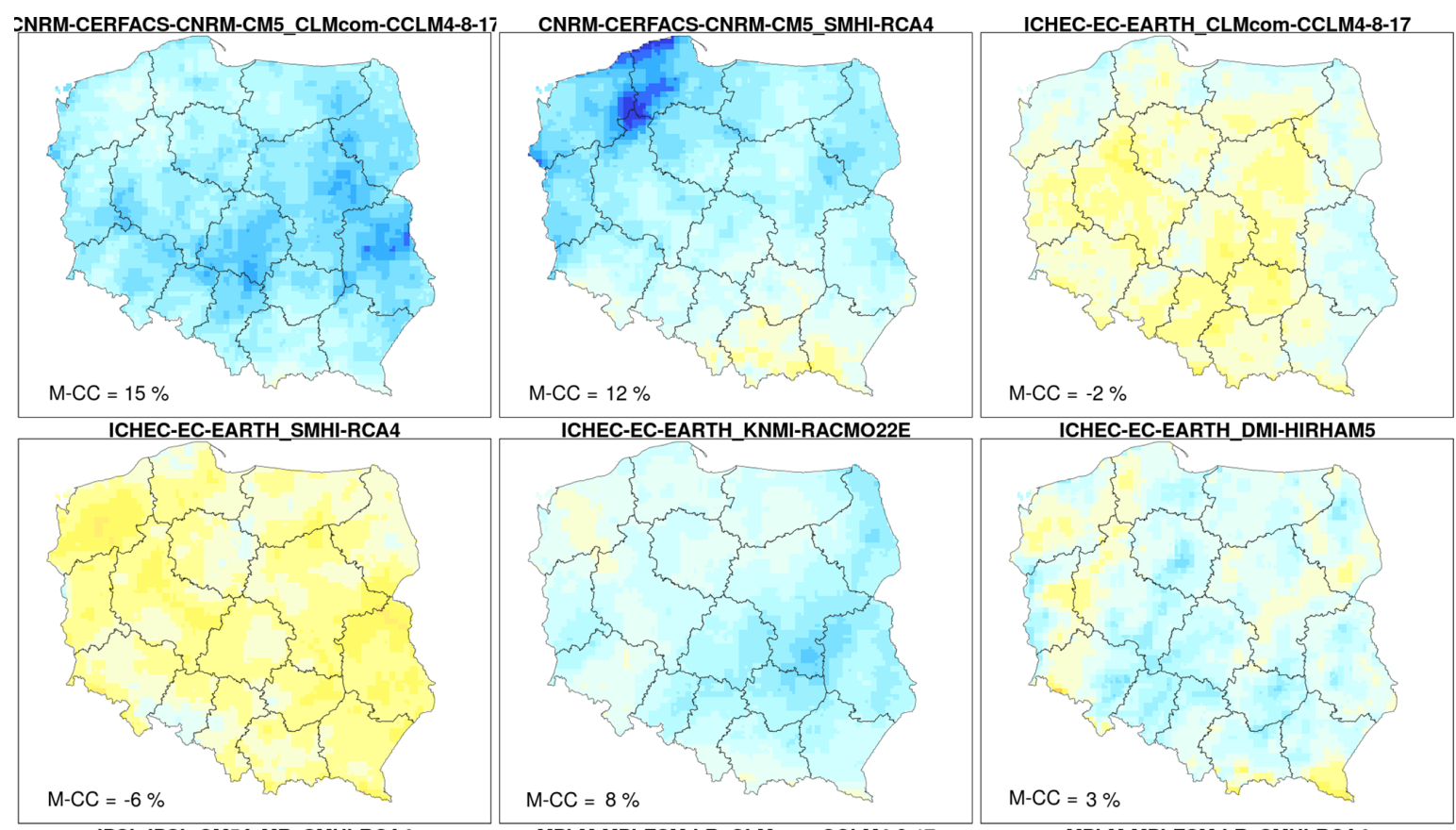

ICHEC-EC-EARTH_KNMI-RACMO22E

ICHEC-EC-EARTH_DMI-HIRHAM5

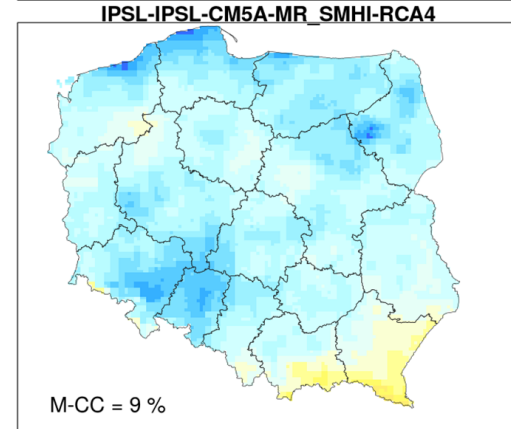

$\mathrm{M}-\mathrm{CC}=8 \%$
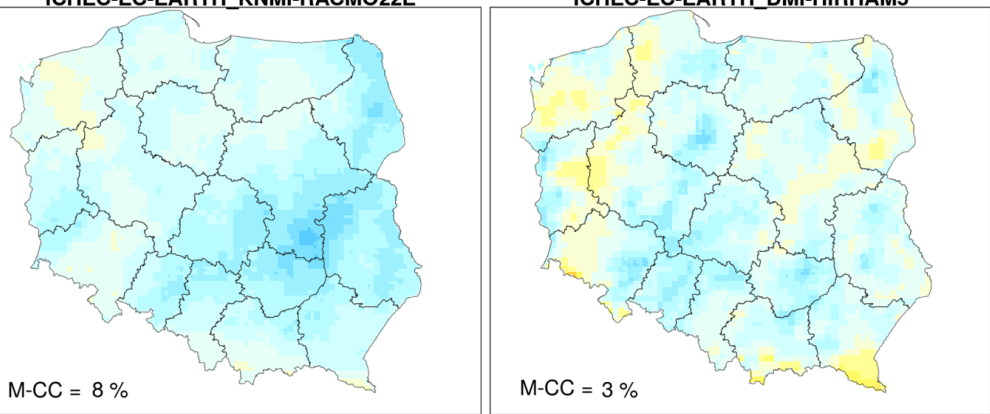

MPI-M-MPI-ESM-LR CLMcom-CCLM4-8-17

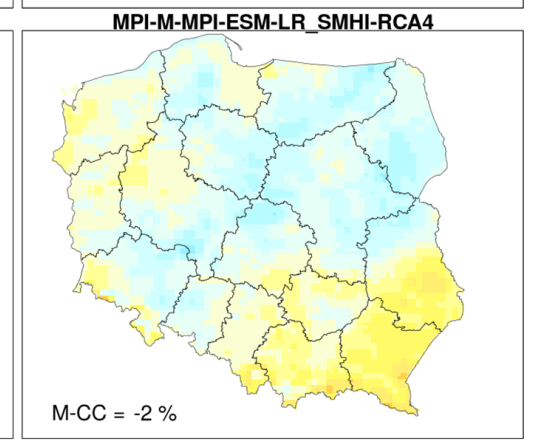

$\mathrm{M}-\mathrm{CC}=-2 \%$
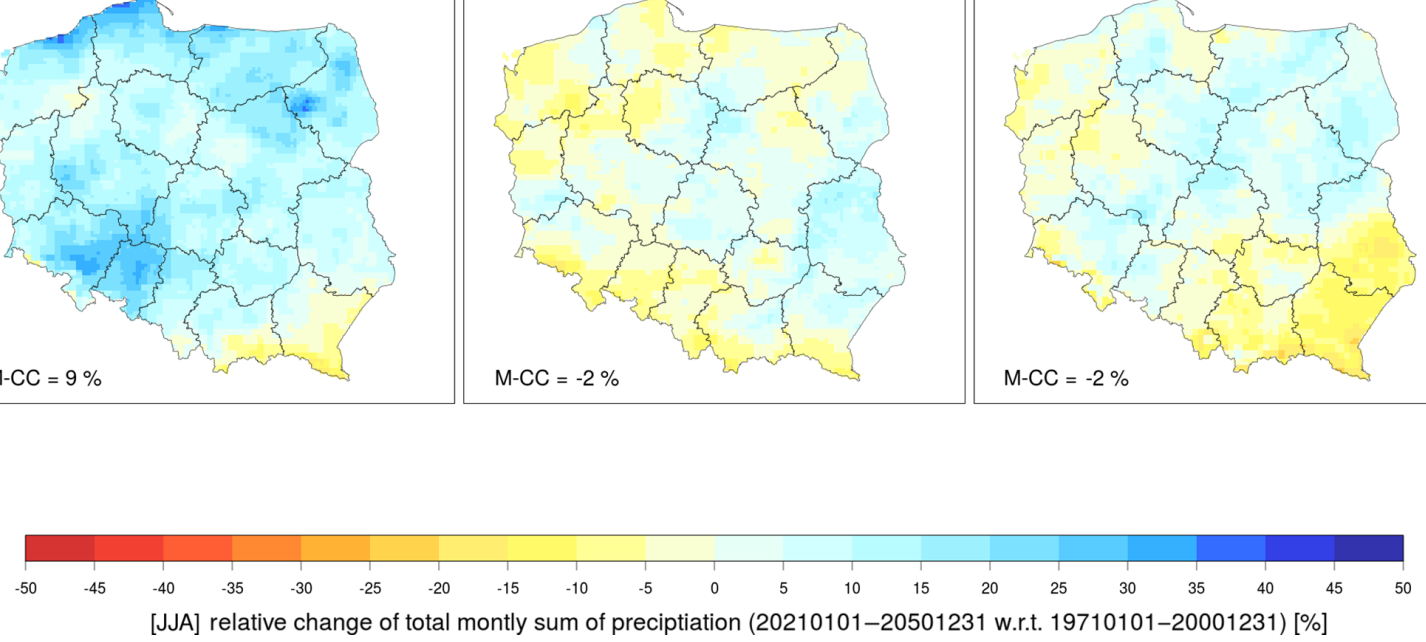

Figure 14. Changes in projected summer means of monthly sums of precipitation by 2071-2100 assuming the RCP8.5 scenario. The maps show the relative changes with regard to the historical period (1971-2000) for the nine adjusted simulations.

\subsection{Data repository at 4TU.Centre for Research Data}

The bias-adjusted files were stored in NetCDF4 format and compiled using the Climate and Forecast (CF) conventions. The data were made available at the 4TU.Centre for Research Data (Mezghani et al., 2016). The files consist of nine bias-adjusted RCM simulations of daily (minimum and maximum) temperature and precipitation for a spatial domain covering the union of Poland and the Vistula and Odra basins for one historical and two future time periods assuming the RCP4.5 and RCP8.5 scenarios. There are 135 files and the total size is $127 \mathrm{~GB}$. The full dataset covering the continuous time period (i.e. 1950-2100) can be obtained upon request from the Norwegian Meteorologi- cal Institute. The CPLCP-GDPT5 dataset presented here is publicly available at https://doi.org/10.4121/uuid:e940ec1a71a0-449e-bbe3-29217f2ba31d.

\subsection{Access through the Climate Impact web portal}

The Climate Impact web portal (http://climateimpact.sggw. pl) developed within the CHASE-PL project presents spatial interactive data on three aspects of climate change in Poland: (1) observations, (2) projections, and (3) impacts. The "Observations" sub-page presents, among other things, the $5 \mathrm{~km}$ resolution gridded precipitation and temperature dataset CPLFD-GDPT5 (Berezowski et al., 2016) that was used in this study as the reference dataset, aggregated to 

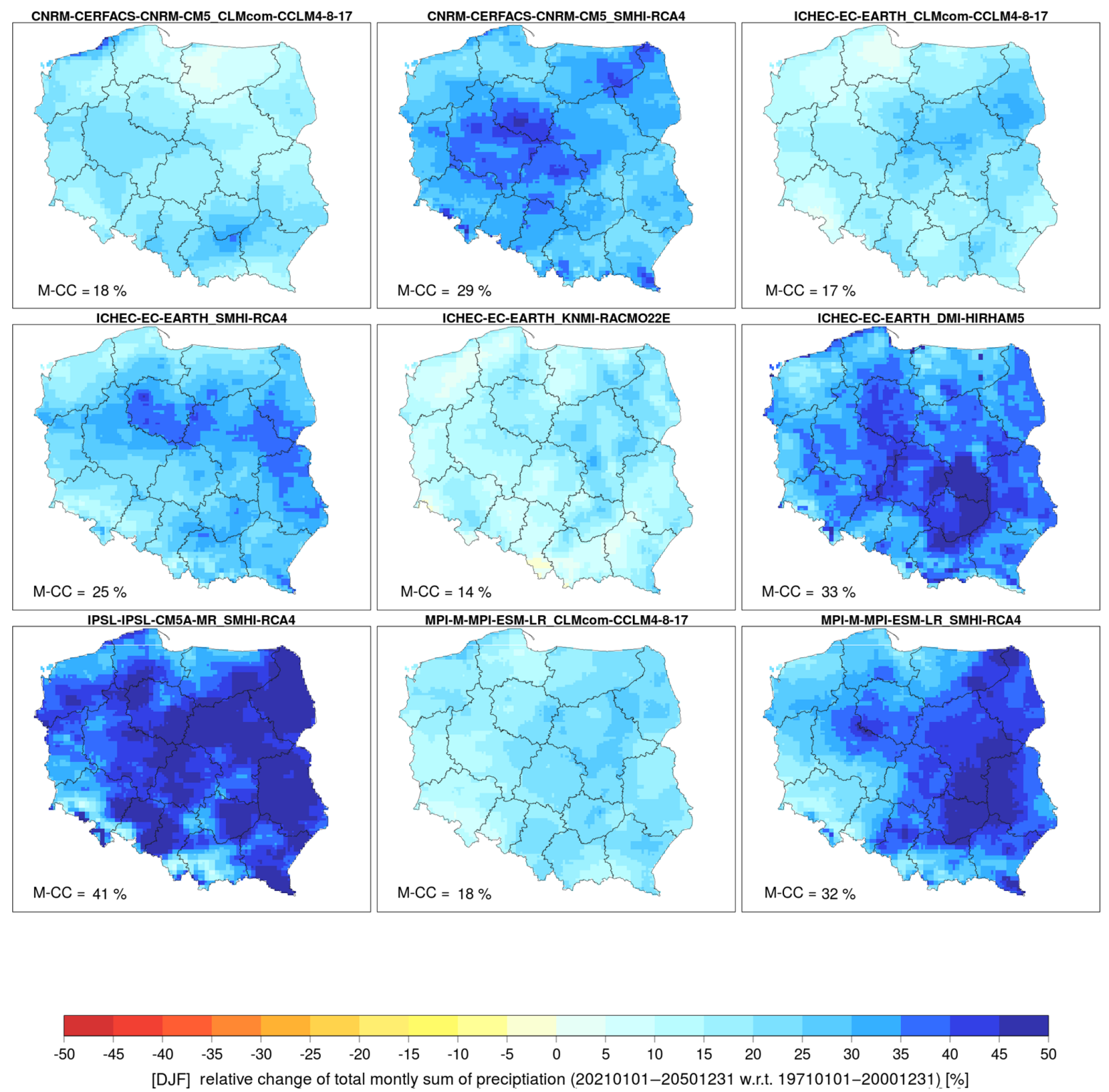

Figure 15. Changes in projected winter means of monthly sums of precipitation by 2071-2100 assuming the RCP8.5 scenario. The maps show the relative changes with regard to the historical period (1971-2000) for all nine adjusted simulations.

monthly/seasonal/annual time series and long-term average values. The "Impacts" sub-page presents maps of climate change impacts on water resources (Piniewski et al., 2017b) obtained from hydrological modelling using SWAT driven by the dataset described in this paper. In this section we focus on the "Projections" sub-page presenting the contents of the CHASE-PL Climate Projections dataset (Fig. 16).

The web-map application was developed using ArcGIS Server, which makes the data available using REST architecture, as well as using the temporal data visualization portal using the JavaScript API for communication between the client and the server. ESRI Geoportal Server was applied for meta-data management. Two language versions, English and
Polish, are available. The geoportal stores in total 180 maps of projected variables (precipitation, minimum and maximum temperature) for two time horizons (near and far future), under two RCPs (4.5 and 8.5), for five temporal aggregation levels (annual and four seasonal), and three ensemble statistics types (5th percentile, median, and 95th percentile). All data are shown as original $5 \mathrm{~km} \times 5 \mathrm{~km}$ raster files. Projected changes are shown, as in this paper, as absolute differences between future and baseline periods for temperature, and as percentage differences for precipitation. Ensemble statistics are calculated for projected changes across all ensemble members. By including three ensemble statistics, the geoportal informs end users both about the magnitude and 


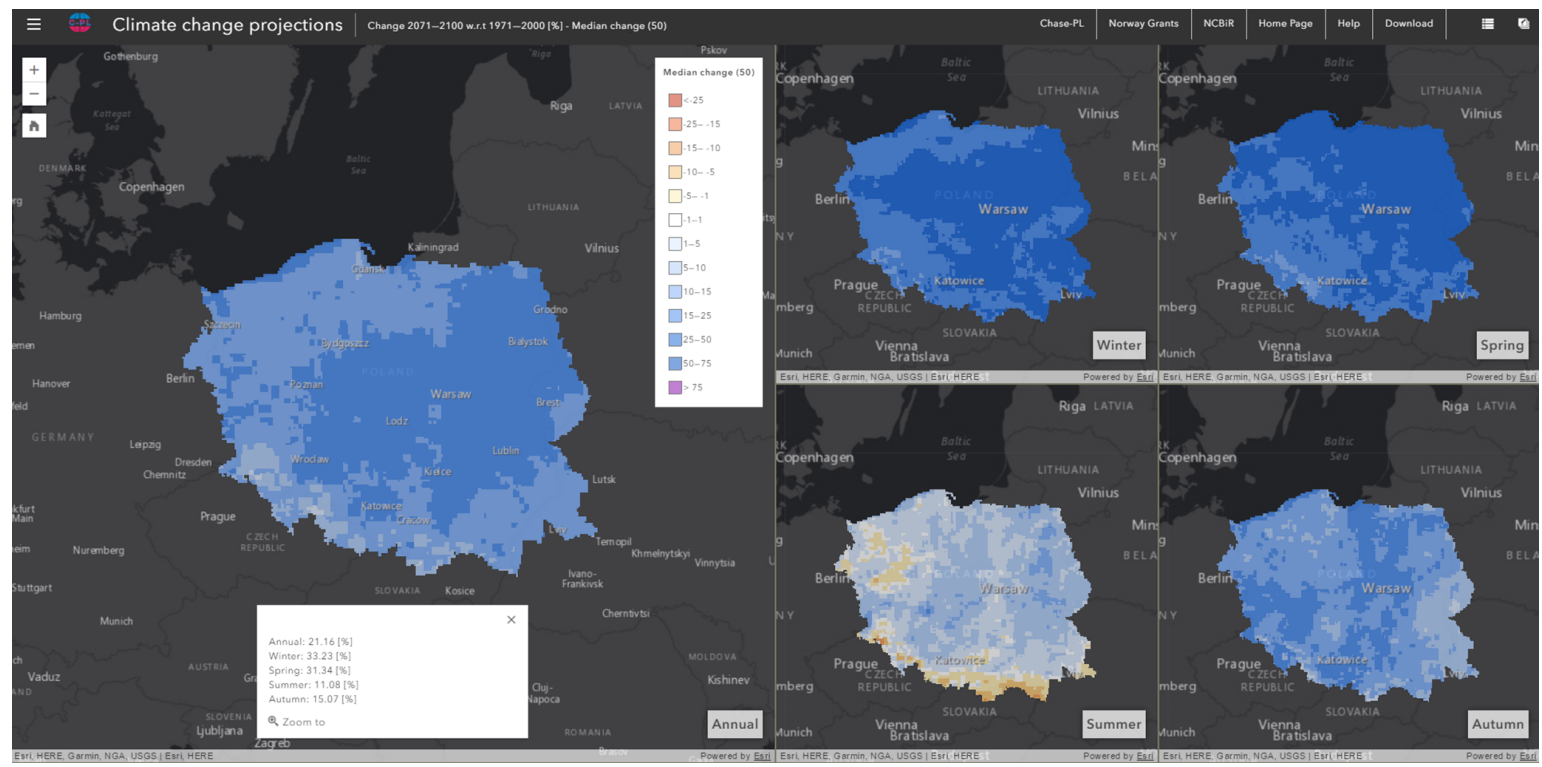

Figure 16. Example of the "Projections" sub-page of the Climate Impact Geoportal http://climateimpact.sggw.pl. The maps show the ensemble median change in mean annual and seasonal precipitation following RCP8.5 in the far future, and the popup window displays interactive values for a selected grid cell from the map.

the spread of change (climate model uncertainty). The webmap application has the following functionalities: (1) metadata searching, (2) searching by location, (3) identification of selected values on the map (simultaneously for all seasons and year), and (4) data download in NetCDF and GeoTIFF formats. The online help and glossary were also created in order to enhance the use of the geoportal among users less advanced in web GIS and/or climate model outputs.

\section{Conclusions}

A recent high-resolution gridded dataset (CHASE-PL Forcing Data "CPLFD-GDPT5") was used as long-term reference dataset produced over the Odra and Vistula basins in Poland and surrounding regions to correct for any systematic bias in daily precipitation and temperatures simulated by nine EURO-CORDEX RCMs. The main purpose was to provide up-to-date climate projections for Poland assuming the new generation of representative concentration pathways.

Results showed that the bias correction method performed very well in reducing the large biases found in the raw data of an ensemble of nine EURO-CORDEX simulations.

Regarding the climate projections, we demonstrated that the climate change signal was not affected by the bias correction method. Yet, any misrepresentation of the former in the RCM, due, for instance, to inherited misrepresentation of (i) the sea surface temperatures and sea ice extent in the northern parts influenced by the Baltic Sea and (ii) topographical features (e.g. the mountains located in the southern parts) could have an influence on the projected temperature and precipitation changes (Wibig et al., 2015). Nevertheless, we assumed that changes in the climate parameters were less affected than their absolute values and hence showed more robust estimates.

Based on the best estimates, projected changes in temperature and precipitation suggest a warmer and wetter climate over Poland for the coming decades, except for summer, during which a decrease in precipitation by less than $7 \%$ is also likely to occur. The warming over Poland is expected to likely vary by $0.3^{\circ} \mathrm{C}$ by $2021-2050$ assuming the intermediate-emission scenario. This accelerates to approximately $5^{\circ} \mathrm{C}$ towards the end of the 21 st century assuming the high-emission scenario. Similarly to temperature, precipitation over Poland is expected to vary by between -7 and $+40 \%$. The highest increases in both temperature and precipitation are expected to occur in winter.

We believe that the CHASE-PL Climate Projection product (CPLCP-CPLFD-GDPT5) available for the period of 150 years (from 1951 to 2100) will serve as the basis for further applications - for instance, to study the impact of climate change over Poland on many sectors (e.g. agriculture, hydrology, ecology, and tourism).

\section{The Supplement related to this article is available online at https://doi.org/10.5194/essd-9-905-2017-supplement.}

Team list. J. E. Haugen designed the bias adjustment experiment and A. Dobler developed the model code and performed the corrections. A. Mezghani estimated the projected changes over Poland and prepared the paper with contributions from all co-authors. 
Competing interests. The authors declare that they have no conflict of interest.

Acknowledgements. We acknowledge the Polish-Norwegian Research Programme operated by the National Centre for Research and Development (NCBiR) under the Norwegian Financial Mechanism 2009-2014 for financial support of the project CHASE-PL (Climate change impact assessment for selected sectors in Poland) in the framework of project contract no. Pol-Nor/200799/90/2014 and the World Climate Research Programme's Working Group on Regional Climate, and the Working Group on Coupled Modelling, former coordinating body of CORDEX and responsible panel for CMIP5. We also thank the climate modelling groups (listed in Table 1 of this paper) for producing and making available their model output. We also acknowledge the Earth System Grid Federation infrastructure - an international effort led by the US Department of Energy's Program for Climate Model Diagnosis and Intercomparison, the European Network for Earth System Modelling, and other partners in the Global Organization for Earth System Science Portals (GO-ESSP). Co-author M. Piniewski is additionally grateful for support from the Alexander von Humboldt Foundation and the Ministry of Science and Higher Education of the Republic of Poland. Finally, we would like to thank the two reviewers, Joanna Wibig and Mirosław Miętus, for their respective positive and constructive comments that helped to improve the paper.

Edited by: David Carlson

Reviewed by: Joanna Wibig and Mirosław Miętus

\section{References}

Benestad, R. E., Achberger, C., and Fernandez, E.: Empiricalstatistical downscaling of distribution functions for daily precipitation, Climate 12/2005, The Norwegian Meteorological Institute, Oslo, Norway, http://www.met.no, 2005.

Berezowski, T., Szcześniak, M., Kardel, I., Michałowski, R., Okruszko, T., Mezghani, A., and Piniewski, M.: CPLFDGDPT5: High-resolution gridded daily precipitation and temperature data set for two largest Polish river basins, Earth Syst. Sci. Data, 8, 127-139, https://doi.org/10.5194/essd-8-127-2016, 2016.

Berg, P., Feldmann, H., and Panitz, H. J.: Bias correction of high resolution regional climate model data, J. Hydrol., 448-449, 8092, https://doi.org/10.1016/j.jhydrol.2012.04.026, 2012.

Boé, J., Terray, L., Habets, F., and Martin, E.: Statistical and dynamical downscaling of the Seine basin climate for hydro-meteorological studies, Int. J. Climatol., 27, 1643-1655, https://doi.org/10.1002/joc.1602, 2007.

Buishand, A. and Beckmann, B.: Development of Daily Precipitation Scenarios at KNMI, Tech. Rep., ECLAT-2 Workshop Report No. 3, Royal Netherlands Meteorological Institute, De Bilt, the Netherlands, 2000.

Buishand, T. A. and Brandsma, T.: Comparison of circulation classification schemes for predicting temperature and precipitation in the Netherlands, Int. J. Climatol., 17, 875-889, 1997.
Buishand, T. A. and Brandsma, T.: Multisite simulation of daily precipitation and temperature in the Rhine basin by nearest-neighbor resampling, Water Resour. Res., 37, 2761-2776, 2001.

Chen, J., Brissette, F. P., Chaumont, D., and Braun, M.: Finding appropriate bias correction methods in downscaling precipitation for hydrologic impact studies over North America, Water Resour Res., 49, 4187-4205, https://doi.org/10.1002/wrcr.20331, 2013.

Christensen, J. H., Boberg, F., Christensen, O. B., and LucasPicher, P.: On the need for bias correction of regional climate change projections of temperature and precipitation, Geophys. Res. Lett., 35, L20709, https://doi.org/10.1029/2008GL035694, 2008.

Déqué, M., Rowell, D. P., Lüthi, D., Giorgi, F., Christensen, J. H., Rockel, B., Jacob, D., Kjellström, E., Castro, M. d., and Hurk, B. v. d.: An intercomparison of regional climate simulations for Europe: assessing uncertainties in model projections, Climatic Change, 81, 53-70, https://doi.org/10.1007/s10584-006-9228-x, 2007.

Ehret, U., Zehe, E., Wulfmeyer, V., Warrach-Sagi, K., and Liebert, J.: HESS Opinions "Should we apply bias correction to global and regional climate model data?", Hydrol. Earth Syst. Sci., 16, 3391-3404, https://doi.org/10.5194/hess-16-3391-2012, 2012.

Fang, G. H., Yang, J., Chen, Y. N., and Zammit, C.: Comparing bias correction methods in downscaling meteorological variables for a hydrologic impact study in an arid area in China, Hydrol. Earth Syst. Sci., 19, 2547-2559, https://doi.org/10.5194/hess-19-25472015, 2015.

Fowler, H. J. and Kilsby, C. G.: Using regional climate model data to simulate historical and future river flows in northwest England, Climatic Change, 80, 337-367, 2007.

Giorgi, F. and Lionello, P.: Climate change projections for the Mediterranean region, Global Planet. Change, 63, 90-104, https://doi.org/10.1016/j.gloplacha.2007.09.005, 2008.

Gudmundsson, L., Bremnes, J. B., Haugen, J. E., and EngenSkaugen, T.: Technical Note: Downscaling RCM precipitation to the station scale using statistical transformations - a comparison of methods, Hydrol. Earth Syst. Sci., 16, 3383-3390, https://doi.org/10.5194/hess-16-3383-2012, 2012.

Haerter, J. O., Hagemann, S., Moseley, C., and Piani, C.: Climate model bias correction and the role of timescales, Hydrol. Earth Syst. Sci., 15, 1065-1079, https://doi.org/10.5194/hess-15-10652011, 2011.

Hagemann, S., Arpe, K., and Bengtsson, L.: Validation of the hydrological cycle of ERA-40, ERA-40 Project Report Series 24, ECMWF, http://www.ecmwf.int, Reading, UK, 2005.

Ines, A. V. and Hansen, J. W.: Bias correction of daily GCM rainfall for crop simulation studies, Agr. Forest Meteorol., 138, 44-53, https://doi.org/10.1016/j.agrformet.2006.03.009, 2006.

Kundzewicz, Z. W. and Matczak, P.: Climate change regional review: Poland: climate change regional review: Poland, WIREs Clim. Change, 3, 297-311, https://doi.org/10.1002/wcc.175, 2012.

Lafon, T., Dadson, S., Buys, G., and Prudhomme, C.: Bias correction of daily precipitation simulated by a regional climate model: a comparison of methods, Int. J. Climatol., 33, 13671381, https://doi.org/10.1002/joc.3518, 2013.

Lanzante, J.: Resistant, robust, and nonparametric techniques for the analysis of climate data. Theory and examples, including ap- 
plications to historical radiosonde station data, Int. J. Climatol., 16, 1197-1226, 1996.

Linden, P. v. d. and Mitchell, J. F. B.: Ensembles: Climate Change and its impacts: summary of research and results from the ENSEMBLES project, European Comission, Met Office Hadley Centre, Exeter, UK, 2009.

Mezghani, A., Dobler, A., and Haugen, J.: CHASE-PL Climate Projections-Gridded Daily Precipitation and Temperature Dataset at $5 \mathrm{~km}$ resolution for Poland, Norwegian Meteorological Institute, Oslo, Norway, Dataset, https://doi.org/10.4121/uuid:e940ec1a-71a0-449e-bbe329217 f2ba31d, 2016.

Muerth, M. J., Gauvin St-Denis, B., Ricard, S., Velázquez, J. A., Schmid, J., Minville, M., Caya, D., Chaumont, D., Ludwig, R., and Turcotte, R.: On the need for bias correction in regional climate scenarios to assess climate change impacts on river runoff, Hydrol. Earth Syst. Sci., 17, 1189-1204, https://doi.org/10.5194/hess-17-1189-2013, 2013.

Osuch, M., Kindler, Romanowicz, R. J., Berbeka, K., and Banrowska, A.: KLIMADA Strategia adaptacji Polski do zmian klimatu w zakresie sektora "Zasoby i gospodarka wodna", Tech. rep., KLIMADA project, IGF PAN, Warsaw, 245 pp., 2012.

Osuch, M., Romanowicz, R. J., Lawrence, D., and Wong, W. K.: Trends in projections of standardized precipitation indices in a future climate in Poland, Hydrol. Earth Syst. Sci., 20, 19471969, https://doi.org/10.5194/hess-20-1947-2016, 2016.

Piani, C. and Haerter, J. O.: Two dimensional bias correction of temperature and precipitation copulas in climate models, Geophys. Res. Lett., 39, L20401, https://doi.org/10.1029/2012GL053839, 2012.

Piniewski, M., Mezghani, A., Szcześniak, M., and Kundzewicz, Z. W.: Regional projections of temperature and precipitation changes: robustness and uncertainty aspects, Meteorol. Z., 26, 223-234, https://doi.org/10.1127/metz/2017/0813, 2017a.

Piniewski, M., Szcześniak, M., Huang, S., and Kundzewicz, Z. W.: Projections of runoff in the Vistula and the Odra river basins with the help of the SWAT model, Hydrol. Res., 48, nh2017280, https://doi.org/10.2166/nh.2017.280, 2017b.

Piotrowski, P. and Jȩdruszkiewicz, J.: Projections of thermal conditions for Poland for winters 2021-2050 in relation to atmospheric circulation, Meteorol. Z., 22, 569-575, https://doi.org/10.1127/0941-2948/2013/0450, 2013.
Pluntke, T., Schwarzak, S., Kuhn, K., Lünich, K., AdynkiewiczPiragas, M., Otop, I., and Miszuk, B.: Climate analysis as a basis for a sustainable water management at the Lusatian Neisse, Meteorology Hydrology and Water Management, Research and Operational Applications, 4, 3-11, https://www.infona.pl//resource/bwmeta1.element. baztech-d8873b7d-b425-414a-9dbe-8451e1ca46f3, 2016.

Romanowicz, R. J., Bogdanowicz, E., Debele, S. E., Doroszkiewicz, J., Hisdal, H., Lawrence, D., Meresa, H. K., Napiórkowski, J. J., Osuch, M., Strupczewski, W. G., Wilson, D., and Wong, W. K.: Climate change impact on hydrological extremes: preliminary results from the Polish-Norwegian Project, Acta Geophys., 64, 477-509, https://link.springer.com/article/10.1515/acgeo-2016-0009, 2016.

Sorteberg, A., Haddeland, I., Haugen, J. E., Sobolowski, S., and Wong, W. K.: Evaluation of distribution mapping based bias correction methods, Tech. Rep., Norwegian Centre for Climate Services (NCCS), Oslo, Norway, Report no. 1/2014, pp. 23, 2014.

Szwed, M., Karg, G., Pińskwar, I., Radziejewski, M., Graczyk, D., Kȩdziora, A., and Kundzewicz, Z. W.: Climate change and its effect on agriculture, water resources and human health sectors in Poland, Nat. Hazards Earth Syst. Sci., 10, 1725-1737, https://doi.org/10.5194/nhess-10-1725-2010, 2010.

Teng, J., Potter, N. J., Chiew, F. H. S., Zhang, L., Wang, B., Vaze, J., and Evans, J. P.: How does bias correction of regional climate model precipitation affect modelled runoff?, Hydrol. Earth Syst. Sci., 19, 711-728, https://doi.org/10.5194/hess-19711-2015, 2015.

Teutschbein, C. and Seibert, J.: Bias correction of regional climate model simulations for hydrological climate-change impact studies: review and evaluation of different methods, J. Hydrol., 456, 12-29, https://doi.org/10.1016/j.jhydrol.2012.05.052, 2012.

Themeß1, M. J., Gobiet, A., and Leuprecht, A.: Empirical-statistical downscaling and error correction of daily precipitation from regional climate models, Int. J. Climatol., 31, 1530-1544, 2010.

Wibig, J., Maraun, D., Benestad, R., Kjellström, E., Lorenz, P., and Christensen, O. B.: Projected Change-Models and Methodology, Regional Climate Studies, Springer, Cham, https: //link.springer.com/chapter/10.1007/978-3-319-16006-1_10, https://doi.org/10.1007/978-3-319-16006-1_10, 2015. 